\title{
Limited forward trafficking of connexin 43 reduces cell-cell coupling in stressed human and mouse myocardium
}

James W. Smyth, ${ }^{1,2}$ Ting-Ting Hong, ${ }^{1,2}$ Danchen Gao, ${ }^{1}$ Jacob M. Vogan, ${ }^{1}$ Brian C. Jensen, ${ }^{2,3}$ Tina S. Fong, ${ }^{1}$ Paul C. Simpson, , ${ }^{1,2,3}$ Didier Y.R. Stainier, ${ }^{1,4}$ Neil C. Chi, ${ }^{2,4}$ and Robin M. Shaw ${ }^{1,2}$

\author{
${ }^{1}$ Cardiovascular Research Institute, ${ }^{2}$ Department of Medicine, UCSF, San Francisco, California, USA \\ ${ }^{3}$ Cardiology Division, San Francisco Veterans Affairs Medical Center, San Francisco, California, USA. \\ ${ }^{4}$ Department of Biochemistry and Biophysics, UCSF, San Francisco, California, USA.
}

\begin{abstract}
Gap junctions form electrical conduits between adjacent myocardial cells, permitting rapid spatial passage of the excitation current essential to each heartbeat. Arrhythmogenic decreases in gap junction coupling are a characteristic of stressed, failing, and aging myocardium, but the mechanisms of decreased coupling are poorly understood. We previously found that microtubules bearing gap junction hemichannels (connexons) can deliver their cargo directly to adherens junctions. The specificity of this delivery requires the microtubule plus-end tracking protein EB1. We performed this study to investigate the hypothesis that the oxidative stress that accompanies acute and chronic ischemic disease perturbs connexon forward trafficking. We found that EB1 was displaced in ischemic human hearts, stressed mouse hearts, and isolated cells subjected to oxidative stress. As a result, we observed limited microtubule interaction with adherens junctions at intercalated discs and reduced connexon delivery and gap junction coupling. A point mutation within the tubulin-binding domain of EB1 reproduced EB1 displacement and diminished connexon delivery, confirming that EB1 displacement can limit gap junction coupling. In zebrafish hearts, oxidative stress also reduced the membrane localization of connexin and slowed the spatial spread of excitation. We anticipate that protecting the microtubule-based forward delivery apparatus of connexons could improve cell-cell coupling and reduce ischemia-related cardiac arrhythmias.
\end{abstract}

\section{Introduction}

Efficient and well-orchestrated spatial propagation of action potentials is achieved through organized cardiomyocyte-cardiomyocyte gap junction coupling $(1,2)$. Changes in the localization and regulation of gap junctions during ischemic and non-ischemic heart disease are well documented (3-6) and contribute to the arrhythmogenic substrate of slowed conduction, unidirectional block, and reentrant circuits (1,7-9). The molecular mechanisms underlying gap junction remodeling remain largely unknown, but their elucidation is paramount to the development of therapies aimed at improving gap junction coupling during disease.

Gap junctions exist as plaques of hexameric arrays containing hundreds to thousands of connexin polypeptide channels spanning the lipid bilayers of adjacent cells (10). To date, over 20 connexin genes have been described in the human genome (11), of which connexin $43(\mathrm{C} \times 43)$ is the primary isoform expressed in gap junctions of the cardiac ventricle (12). Six connexin molecules complex to form a connexon hemichannel, which, when inserted into the plasma membrane, can bind with a hemichannel on an opposing cell, creating a conduit that connects the cytoplasms of both cells (10). Gap junctions are concentrated at intercalated discs, discrete regions of cardiomyocyte-cardiomyocyte coupling in the heart, where they interact intimately with adherens junctions (13-16).

Microtubules have a well-studied role in the trafficking of Cx43 to the plasma membrane (17-21). Individual microtubules exist in a state of dynamic instability and typically emanate from the microtubule organizing center (MTOC) at the centrosome of

Conflict of interest: The authors have declared that no conflict of interest exists. Citation for this article: J. Clin. Invest. 120:266-279 (2010). doi:10.1172/JCI39740. each cell. As such, microtubules can be considered polarized, with a dynamic plus end furthest from the MTOC and a more stable minus end anchored at the MTOC (22). Several proteins have been identified that are intimately associated with the dynamic plus ends of microtubules and are termed "plus end binding proteins" (23). Of these, EB1 has been found to be involved in the targeted delivery of $\mathrm{Cx} 43$ to adherens junctions (24) by tethering microtubule plus ends at adherens junctions (25-27), facilitating delivery of their Cx43-containing vesicular cargo (24).

Oxidative stress is a component of most forms of heart disease, such as ischemia-reperfusion injury (28) and chronic ischemic injury (29-31), and may alone result in congestive heart failure (32). There have been several reports of deleterious effects on the cardiomyocyte cytoskeleton, particularly in microtubules, as a result of ischemic and oxidative stress (33-35). Given the relatively short half-life of Cx43 hemichannels at the plasma membrane (36-38), their dependence on microtubules for delivery to the plasma membrane $(18,19$, $24)$, and the diminished gap junction coupling associated with cardiac pathologies (3-5), we investigated whether forward trafficking of $\mathrm{Cx} 43$ was perturbed in the stressed/diseased myocardium, thus contributing to losses in cell-cell electrical coupling.

In this study, we report the surprising observation that oxidative stress displaces EB1 from microtubule plus ends, which limits microtubule growth patterns and delivery of $\mathrm{Cx} 43$ to the plasma membrane. We found EB1 levels to be reduced at intercalated discs in end-stage human ischemic cardiomyopathy and in adult mouse hearts exposed to acute ischemia-reperfusion injury or acute oxidative stress alone. Using primary mouse neonatal ventricular myocytes and an inducible Cx43-EYFP cell line with total internal reflection microscopy (TIRFm), we found that EB1 displacement 
correlates with reduced real-time delivery of $\mathrm{Cx} 43$ to the plasma membrane during oxidative stress. A point mutation in EB1 conferring reduced affinity for tubulin (mimicking EB1 displacement) was sufficient to reduce $\mathrm{Cx} 43$ delivery, confirming the role of EB1 displacement in reducing cell-cell coupling. Forward trafficking was also confirmed by a decrease in surface $\mathrm{Cx} 43$ in the presence of oxidative stress and an endocytosis inhibitor in primary adult mouse ventricular cardiomyocytes, as well as in HeLa cells. We also found, using transgenic zebrafish lines, that oxidative stress alters gap junction membrane localization and causes arrhythmogenic slowing of conduction. These data together support our hypothesis that perturbed EB1-tipped, microtubule-dependent forward trafficking of $\mathrm{Cx} 43$ to the plasma membrane is a significant contributor to losses in cell-cell coupling during heart disease.

\section{Results}

$C \times 43$ and EB1 are reduced at intercalated discs in human end-stage ischemic cardiomyopathy. Loss of cardiomyocyte electrical coupling through downregulation and altered localization of gap junctions is a key characteristic of both acute and chronic cardiomyopathy (3-5). Given the recent identification of the plus end protein EB1 as an important component of the microtubule-based targeted delivery of $\mathrm{Cx} 43$ hemichannels to the adherens junctions of the intercalated disc (24), we were curious about the integrity of this forward trafficking machinery in explanted ischemic human heart tissue (representative hearts in Supplemental Figure 1; supplemental material available online with this article; doi:10.1172/JCI39740DS1). Confocal fluorescent immunohistochemistry of cryosections revealed a reduction in $\mathrm{Cx} 43$ levels at the intercalated disc (Figure 1, A and B) and a higher amount of intracellular Cx43 not associated with $\mathrm{N}$-cadherin. Biochemical separation of tissue lysates into soluble (non-junctional) versus insoluble (junctional) fractions $(39,40)$ yielded data consistent with this finding. There was less junctional and correspondingly more non-junctional $\mathrm{Cx} 43$ in ischemic versus non-failing heart tissues (Figure 1C). Furthermore, immunodetectable EB1 was found throughout the cardiomyocyte but was normally enriched in regions coincident with $\mathrm{N}$-cadherin at the intercalated disc (Figure 1D). The overall EB1 signals were comparable in tissues from end-stage ischemic cardiomyopathy, but enrichment of EB1 at the intercalated disc was not observed (Figure 1, D and E). No significant difference in levels of $\mathrm{N}$-cadherin, $\mathrm{Cx} 43$, or EB1 from total protein lysate was detected (Supplemental Figure 2). These results suggest that a reduction in EB1-tipped microtubules at the intercalated disc might lead to diminished $\mathrm{Cx} 43$ forward trafficking to plaques and therefore contribute to loss of cell-cell coupling during ischemic heart disease.

Oxidative stress alters $\mathrm{C} x 43$ localization and disrupts the microtubulebased trafficking machinery in adult mouse heart. Oxidative stress is present during acute ischemic injury, reperfusion injury, and chronic cardiomyopathy (28-31). In order to directly study the impact of isolated oxidative stress on $\mathrm{Cx} 43$ and EB1 localization in the heart, we used Langendorff-perfused adult mouse heart preparations that were exposed to either ischemia-reperfusion injury or $\mathrm{H}_{2} \mathrm{O}_{2}$. We found that comparable levels of ROS are present in hearts exposed to both conditions (Figure 2A). Moreover, $\mathrm{H}_{2} \mathrm{O}_{2}$ induced oxidative stress alone was sufficient to alter localization of $\mathrm{Cx} 43$ and reduce its relative levels by over $34 \%$ at the intercalated disc (Figure 2, B and C). As a complementary biochemical assay, co-immunoprecipitation was performed on lysates from the same adult mouse hearts. In both $\mathrm{H}_{2} \mathrm{O}_{2}$-perfused and ischemia-reperfu- sion-treated hearts, less $\mathrm{Cx} 43$ was associated with $\mathrm{N}$-cadherin (Figure $2 \mathrm{D}$, top 2 rows), despite intact $\mathrm{N}$-cadherin/ $\beta$-catenin complexing (Figure 2D, bottom 2 rows), indicating that oxidative stress limits the localization of $\mathrm{Cx} 43$ to the intercalated disc. Moreover, co-immunoprecipitation of EB1 with $\mathrm{N}$-cadherin was also reduced (Figure 2D, third row), consistent with our observations in ischemic human tissue (Figure 1C).

It might be argued from the data in Figure 2, B and C, that diminished $\mathrm{Cx} 43$ localization at the intercalated disc is a result of enhanced internalization or lateralization away from $\mathrm{N}$-cadherin containing membrane rather than failed delivery. Cx43 internalization has been shown to be dependent upon the GTPase dynamin (41), which can be specifically blocked using the endocytosis inhibitor Dynasore (42). We exposed adult mouse ventricular cardiomyocytes to $\mathrm{H}_{2} \mathrm{O}_{2}$ in the presence or absence of Dynasore in order to specifically address the role of perturbed forward trafficking in reduced surface expression of $\mathrm{Cx} 43$. Surface protein biotinylation revealed that Dynasore alone increased surface levels of $\mathrm{Cx} 43$ as expected, and that oxidative stress decreased these levels despite endocytosis inhibition (Figure 2E). Similarly, in a stable HeLa cell line expressing $\mathrm{Cx} 43$, results indicate a significant drop in surface Cx43 levels during oxidative stress despite inhibition of endocytosis (Supplemental Figure 3), further supporting the involvement of forward trafficking in reduced cell-cell coupling during oxidative stress. Just as in ischemic human myocardium, $\mathrm{Cx} 43$ levels were decreased despite preserved N-cadherin levels. Decreased plaque formation in the presence of oxidative stress is therefore due in part to impairment of the connexon forward trafficking machinery.

EB1 is displaced during oxidative stress, altering microtubule growth and limiting interaction with the plasma membrane. Oxidative stress is known to interfere with microtubule integrity and growth (33-35). Using HeLa cells, we performed confocal immunofluorescent detection of $\alpha$-tubulin and EB1 (Figure 3A). Under control conditions, EB1 (green) displayed a typical comet-shaped phenotype at the plus ends of microtubules (red). In $\mathrm{H}_{2} \mathrm{O}_{2}$-treated cells, microtubules appeared intact, yet EB1 comets were markedly reduced (Figure 3, A and B). In fact, the diffuse distribution of EB1 in $\mathrm{H}_{2} \mathrm{O}_{2}$ treated cells suggests a displacement of EB1 from the plus ends of dynamic microtubules which could hinder search and capture at the plasma membrane. In order to visualize the impact of oxidative stress on the interaction of EB1-tipped microtubules with the plasma membrane in real-time, we used TIRFm, which limits the depth of field to approximately $50-100 \mathrm{~nm}$ from the coverslip surface. This approach allows visualization of EB1 dynamics in the vicinity of cortical membrane $(43,44)$ (Figure 3C). HeLa cells ectopically expressing EB1-EGFP were seeded on coverslips coated with $\mathrm{N}$-cadherin. Images of EB1-EGFP were presented prior to exposure to $\mathrm{H}_{2} \mathrm{O}_{2}$, after 45 minutes of exposure to $\mathrm{H}_{2} \mathrm{O}_{2}$, and 45 minutes following washout after 60 minutes of exposure to $\mathrm{H}_{2} \mathrm{O}_{2}$ (Figure 3D). Two minutes of acquisition images were collapsed into a single frame so that each line indicates an individual EB1-tipped microtubule growth episode. Note the reduction in size within the first hour of oxidative stress and recovery comparable to control conditions following $\mathrm{H}_{2} \mathrm{O}_{2}$ washout. Shorter lines indicate less movement and less interaction with cortical membrane in the presence of oxidative stress. Videos used to compile Figure 3D are available as Supplemental Video 1 (control), Supplemental Video 2 (45 minutes of $\mathrm{H}_{2} \mathrm{O}_{2}$ ), and Supplemental Video 3 (45 minutes after wash). EB1 density computations in Figure 3E quantify the reduction in EB1-EGFP interaction with the plasma membrane during oxida- 

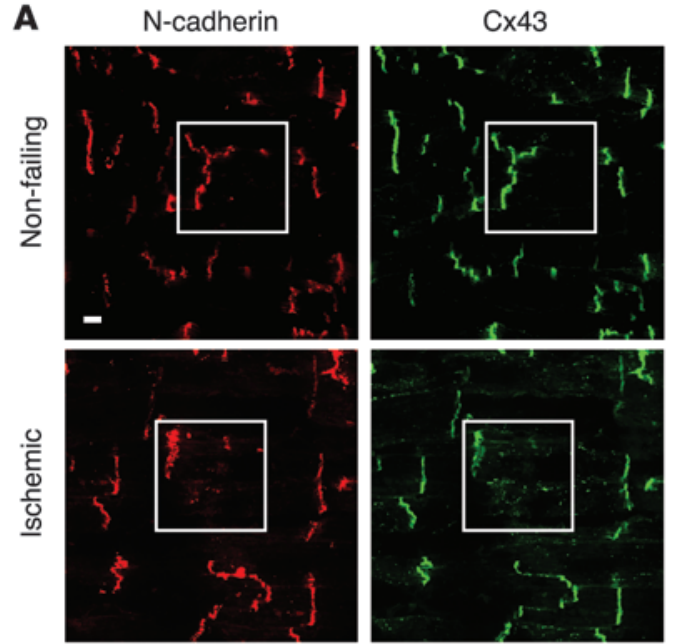

C
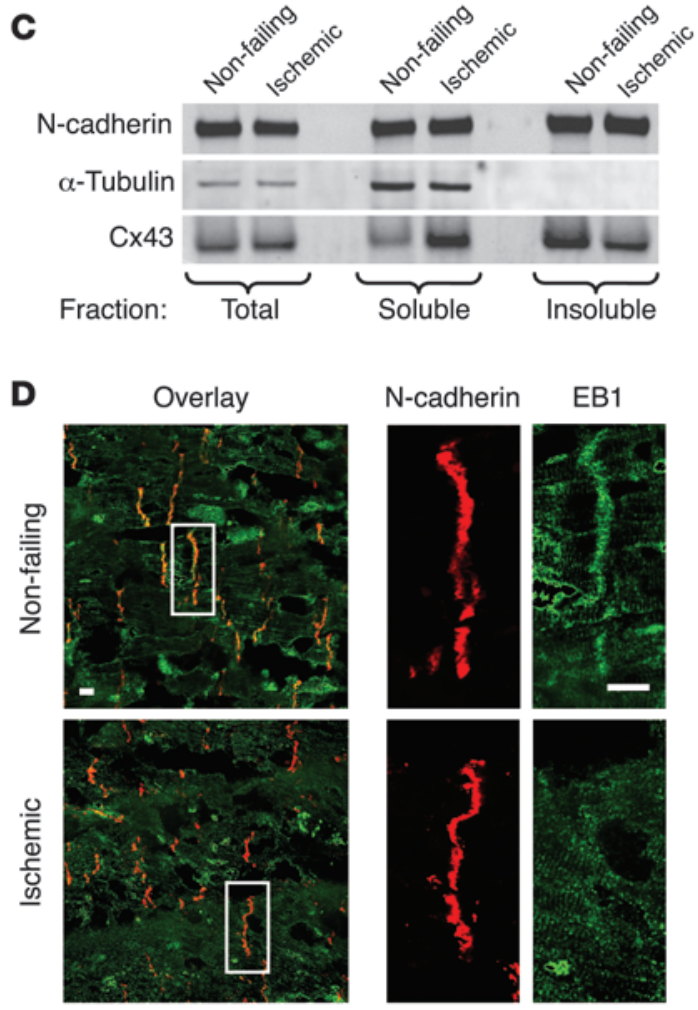

B

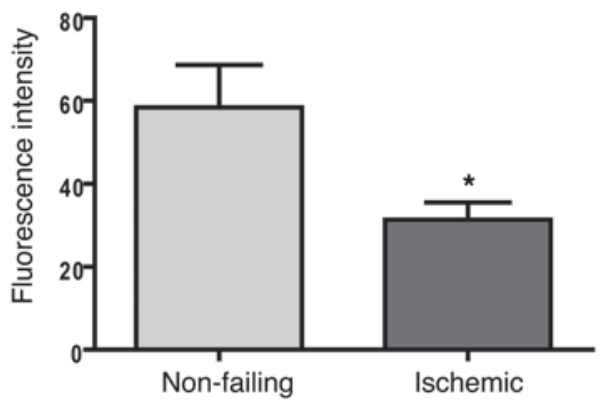

\section{Figure 1}

Levels of Cx43 and EB1 at the intercalated disc are reduced with end-stage ischemic cardiomyopathy. Immunofluorescence labeling of cryosections from snap-frozen non-failing and end-stage ischemic explanted human heart tissue. (A) Human heart Cx43 immunofluorescence. $\mathrm{N}$-cadherin in red and Cx43 in green, with enlarged overlay images. N-cadherin was used as a marker for the intercalated disc (arrows). (B) Cx43 at intercalated discs. Quantification of Cx43 fluorescence intensity in regions also positive for $\mathrm{N}$-cadherin expression. (C) Tissue fractionation. Triton $\mathrm{X}-100$-based fractionation of soluble (cytoplasmic) and insoluble (junctional) protein from tissue detected by Western blot analysis, quantified in bar charts. (D) EB1 immunofluorescence. N-cadherin in red and EB1 in green with enlarged panels at right displaying comparable intercalated discs. (E) EB1 enrichment at intercalated discs. Quantification of EB1 fluorescence intensity in regions also positive for N-cadherin expression. Original magnification, $\times 60$. Scale bars: $10 \mu \mathrm{m}$. Data are representative of 4 non-failing and 4 end-stage ischemic explanted hearts. Statistical analysis was performed using the Student's unpaired $t$ test. Values represent mean \pm SEM. ${ }^{\star} P<0.05,{ }^{\star \star} P<0.01$.

tive stress. Similar data were obtained in primary neonatal mouse ventricular cardiomyocytes transduced with lentivirus encoding EB1-EGFP. A significant and reversible reduction in numbers of EB1-tipped microtubules approaching the cell cortex was observed during oxidative stress (Supplemental Figure 4). These data are temporally consistent with initial detection of intracellular ROS within 60 minutes of exposure to $200 \mu \mathrm{m} \mathrm{H}_{2} \mathrm{O}_{2}$, as determined by dihydroethidium (Supplemental Figure 5). 
A

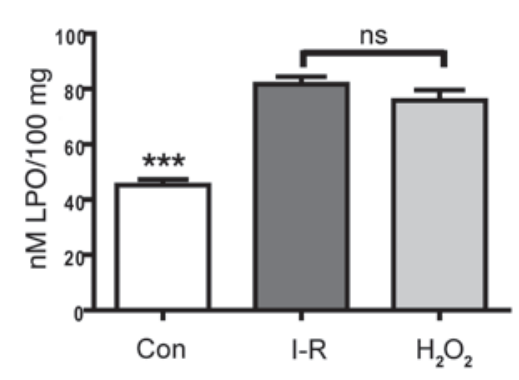

C

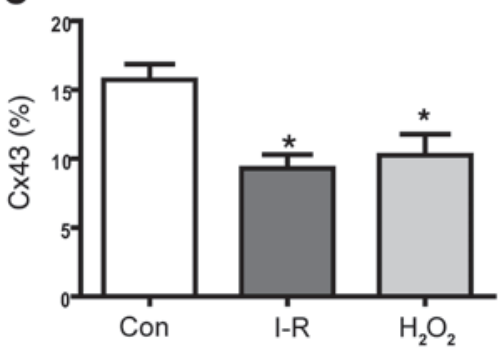

B
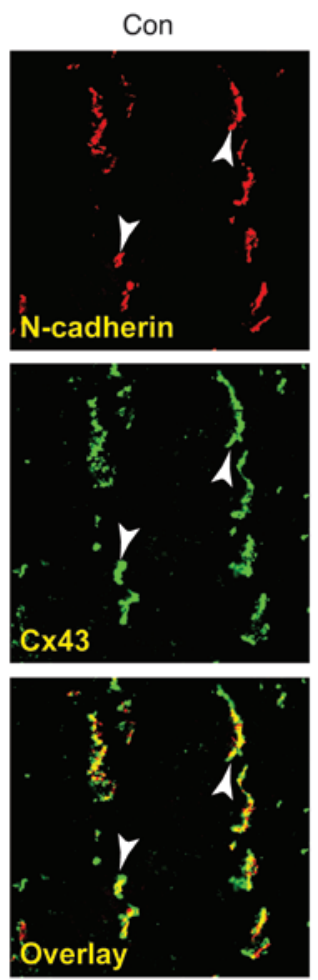
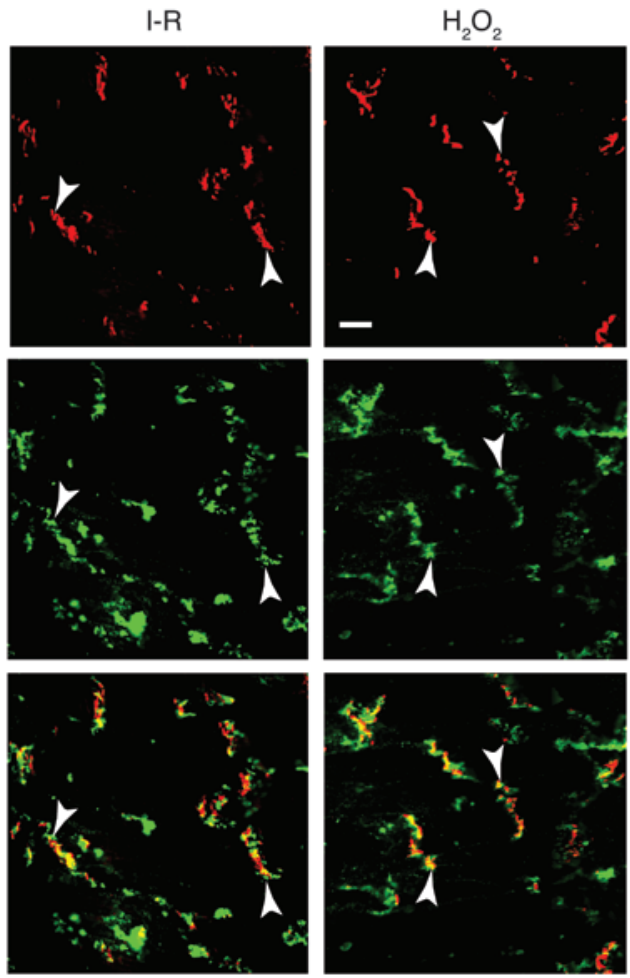

$\mathbf{E}$

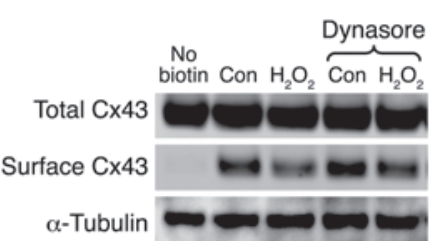

\section{Figure 2}

The oxidative stress component of ischemia-reperfusion injury is sufficient to disrupt EB1/adherens junction association and perturb Cx43 forward trafficking. Hearts from 6- to 8-week-old male C57BL/6 mice were maintained using a Langendorff perfusion apparatus for 30 minutes, followed either by 90 minutes of normal perfusion (control), 30 minutes of ischemia, and 60 minutes of reperfusion (I-R) or by 90 minutes of perfusion with $10 \mu \mathrm{M} \mathrm{H}_{2} \mathrm{O}_{2}$. (A) The lipid hydroperoxide (LPO) assay was used to quantify levels of oxidative stress induced by each treatment. (B) Immunofluorescence labeling of $\mathrm{N}$-cadherin (red) and $\mathrm{Cx} 43$ (green) in cryosections from snap-frozen hearts. Arrows indicate intercalated discs. Original magnification, $\times 60$. Scale bar: $10 \mu \mathrm{m}$. (C) Percentage of Cx43 at intercalated discs. Quantification of Cx43 fluorescence intensity in regions also positive for $\mathrm{N}$-cadherin expression relative to total $\mathrm{Cx} 43$ expression. (D) Co-immunoprecipitation of $\mathrm{Cx} 43$, EB1, and $\beta$-catenin with $\mathrm{N}$-cadherin detected by Western blot analysis. (E) Surface protein biotinylation of isolated adult mouse cardiomyocytes cultured for 4 hours in the presence or absence of $10 \mu \mathrm{M} \mathrm{H}_{2} \mathrm{O}_{2}$ detected by Western blot analysis. Dynasore was used to inhibit endocytosis. Con, control. Statistical analysis was performed using a 1-way ANOVA with Bonferroni post-hoc correction. Values represent 3 hearts from each condition; mean \pm SEM. ${ }^{*} P<0.05$ compared with control. ${ }^{* \star *} P<0.001$ compared with $\mathrm{I}-\mathrm{R}$ or $\mathrm{H}_{2} \mathrm{O}_{2}$.

Having found that EB1 is displaced from microtubule plus ends during oxidative stress (Figure 3), we were interested in how the dynamic instability of microtubules was affected. Using spinningdisk confocal microscopy to visualize ectopically expressed $\alpha$-tubulin-EGFP in HeLa cells plated on N-cadherin-coated coverslips, we tracked individual microtubules and quantified their dynamics (Figure 4A). Data presented in Supplemental Table 1 show that oxidative stress significantly perturbed microtubule dynamics, and Figure 4B illustrates its negative impact on microtubule growth rates. Time lapse videos of 5-minute acquisitions of cells expressing $\alpha$-tubulin-EGFP in the presence or absence of $\mathrm{H}_{2} \mathrm{O}_{2}$ are avail- able as Supplemental Videos 4 and 5, respectively. Moreover, fewer microtubules were found to approach the cell cortex during the 5-minute acquisition period, which may have reduced microtubulebased delivery of vesicular cargo to the plasma membrane during oxidative stress (Figure 4C).

Oxidative stress limits forward trafficking of Cx43 to the plasma membrane. To test whether the reduction in $\mathrm{Cx} 43$ plaque formation (Figures 1 and 2 and Supplemental Figure 3 ) was a direct result of perturbed forward trafficking as a consequence of EB1 displacement and slowed microtubule dynamics during oxidative stress (Figures 3 and 4), we developed an assay of $\mathrm{Cx} 43$ delivery by creating an inducible 
A
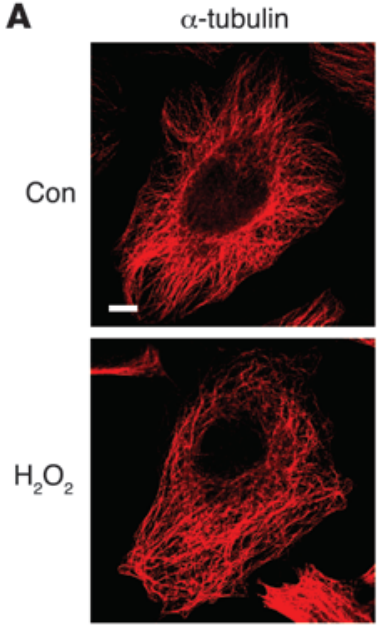

B

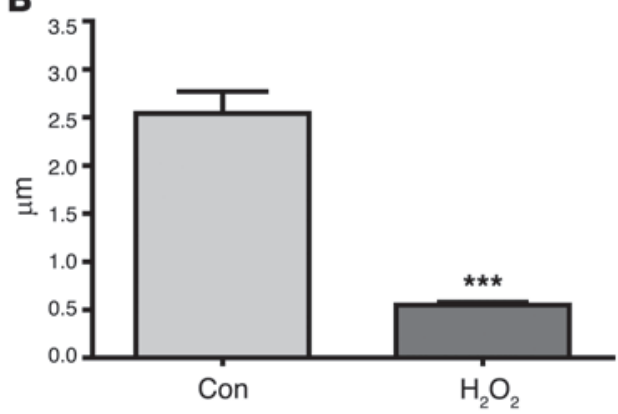

EB1
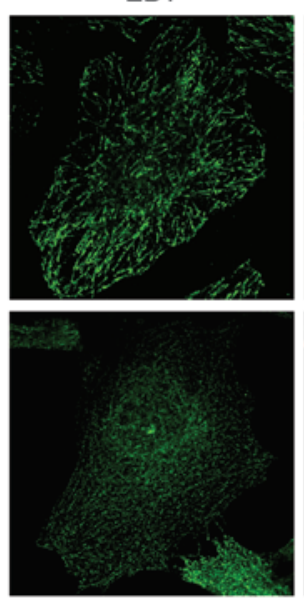

Overlay
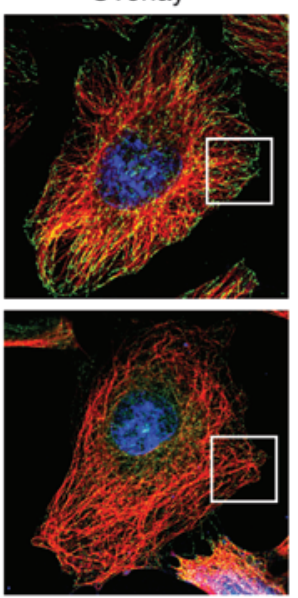
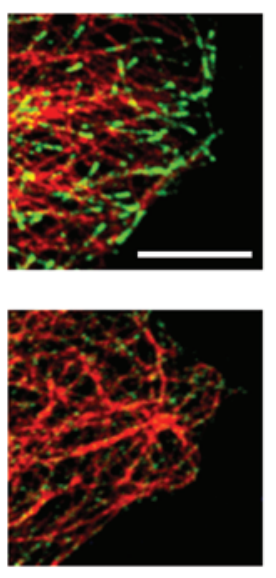

C

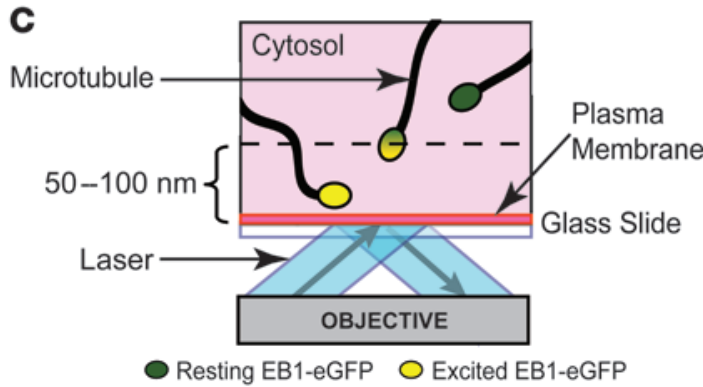

Resting EB1-eGFP O Excited EB1-eGFP

D

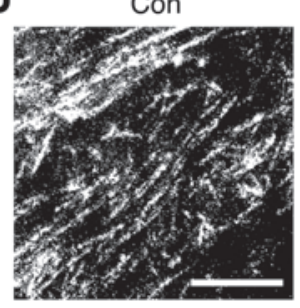

$\mathrm{H}_{2} \mathrm{O}_{2}$

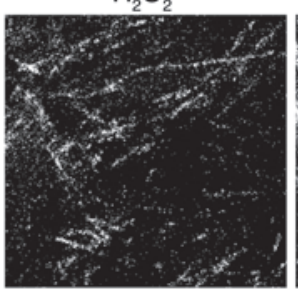

Wash

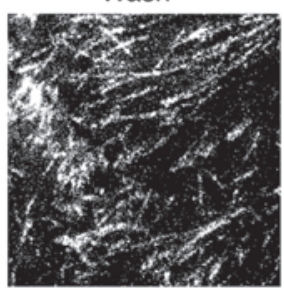

E

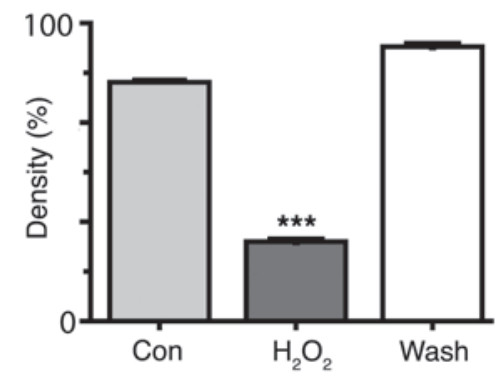

Figure 3

EB1 is displaced off of microtubule plus ends and interacts less with the plasma membrane during oxidative stress. (A) HeLa cells exposed to $200 \mu \mathrm{M} \mathrm{H}_{2} \mathrm{O}_{2}$ for 4 hours were fixed in ice-cold methanol, and confocal immunofluorescence detection of EB1 (green) and $\alpha$-tubulin (red) was performed with nuclei counterstained using TO-PRO-3 (blue). Enlargement of a cell-cell border region (scale bar: $10 \mu \mathrm{m}$ ) shows a reduction in EB1 at the microtubule plus end. Original magnification, $\times 60$. (B) Quantification of EB1 comet length. (C) Schematic representation of TIRFm detection of EB1-EGFP at dynamic microtubule plus ends interacting with the plasma membrane. (D) EB1 movement visualized by TIRFm. HeLa cells were transfected with EB1-EGFP 24 hours prior to imaging. Maximum-intensity projections of compiled images from 2-minute TIRFm acquisitions before, after 45 minutes of exposure to $200 \mu \mathrm{M} \mathrm{H}_{2} \mathrm{O}_{2}$, and 45 minutes following end of exposure to $200 \mu \mathrm{M} \mathrm{H}_{2} \mathrm{O}_{2}$. Original magnification, $\times 100$. Scale bar: $10 \mu \mathrm{m}$. (E) Density of EB1 comet events detectable by TIRFm. Data are representative of 3 separate experiments. Statistical analysis was performed using the Student's unpaired $t$ test $(\mathbf{B})$ and a 1-way ANOVA with Bonferroni post-hoc correction (E). Data represent mean \pm SEM. ${ }^{* *} P<0.001$ compared with control.

clonal HeLa cell line that expressed Cx43-enhanced yellow fluorescent protein (Cx43-EYFP) under transcriptional regulation of the TRE $\mathrm{MOD}_{\mathrm{D}}$ conditional promoter (45). Timing experiments revealed that Cx 43 -EYFP was in the Golgi apparatus at 2 hours and then appeared on the plasma membrane between 2.5 and 4 hours after exposure to doxycycline. TIRFm was employed to visualize real-time $\mathrm{Cx} 43$ hemichannel delivery to the plasma membrane within this time window while in the presence or absence of $\mathrm{H}_{2} \mathrm{O}_{2}$ (Figure $5 \mathrm{~A}$ ). By introducing $\mathrm{H}_{2} \mathrm{O}_{2}$ after Cx43-EYFP was already in the Golgi apparatus, we also controlled for the possible effects of $\mathrm{H}_{2} \mathrm{O}_{2}$ on transcription. A significant reduction in newly delivered Cx43-EYFP levels detectable by TIRFm was observed during oxidative stress (Figure 5, B and D), even though these cells expressed the same levels of Cx43-EYFP (Figure 5C), indicating a failure of connexon delivery to the plasma membrane. Timelapse videos from which frames were used to compile Figure 5B 
A

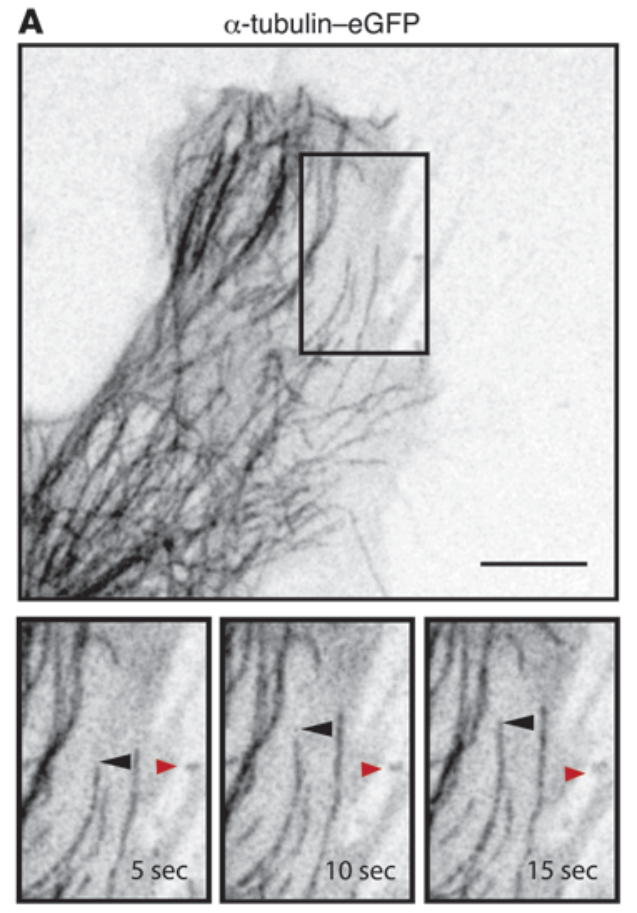

B
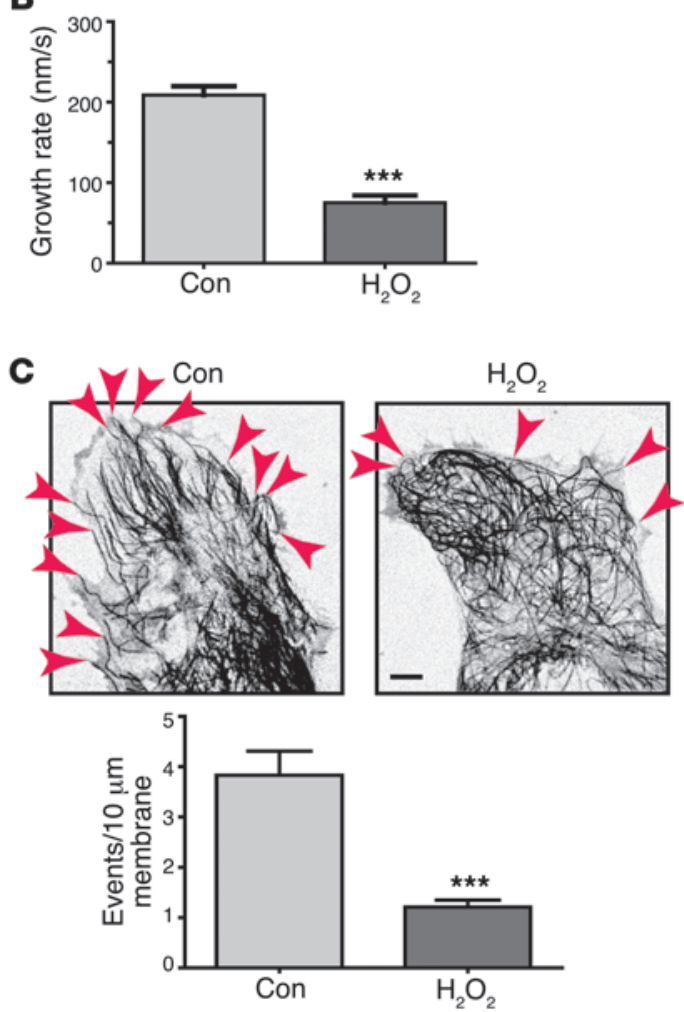

Figure 4

Microtubule dynamics are decreased and fewer microtubules approach the cell cortex during oxidative stress. HeLa cells were transfected with $\alpha$-tubulin-EGFP and visualized by spinning-disk confocal microscopy to capture 5-minute time courses 18 hours after transfection. When appropriate, $\mathrm{H}_{2} \mathrm{O}_{2}$ was added to a final concentration of $200 \mu \mathrm{M} 45$ minutes prior to imaging. (A) Individual microtubules were tracked using ImageJ and the MTrackJ plug-in. Red arrowheads represent a static point of reference; black arrowheads represent a dynamic microtubule plus end. (B) Quantification of microtubule growth rate. (C) Arrows point to microtubules approaching cell cortex during a 5-minute acquisition time. Graph illustrates quantification of the numbers of microtubules approaching the cell cortex $/ 10 \mu \mathrm{m}$ membrane. Original magnification, $\times 100$. Scale bars: $10 \mu \mathrm{m}$. Results are representative of 3 separate experiments. Statistical analysis was performed using the Student's unpaired $t$ test. Values represent mean \pm SEM. ${ }^{* * *} P<0.001$

are available as Supplemental Video 6 (control) and Supplemental Video $7\left(\mathrm{H}_{2} \mathrm{O}_{2}\right)$. Figure $5 \mathrm{E}$ shows the complementary biochemical assay of surface biotinylation, which was used to quantify the effects of oxidative stress on $\mathrm{N}$-cadherin and de novo $\mathrm{Cx} 43$ expression at the plasma membrane. Exposure to $\mathrm{H}_{2} \mathrm{O}_{2}$ resulted in a reduction in $\mathrm{Cx} 43$ levels at the cell surface, while $\mathrm{N}$-cadherin levels remained unchanged.

Displacement of EB1 from microtubules is sufficient to reduce surface levels of $C x 43$. Having found that reduced forward trafficking of $\mathrm{Cx} 43$ occurs during oxidative stress (Figure 5), and that EB1 is displaced off of microtubule plus ends (Figure 3), we were interested in whether EB1 displacement is causative in limiting $\mathrm{Cx} 43$ forward trafficking to the plasma membrane. A previously reported point mutation, $\mathrm{K} 89 \mathrm{E}$, was introduced within the tubulin binding domain of EB1 (Figure 6A) with the aim of inhibiting EB1-tubulin binding (46). Immunofluorescent detection of ectopically expressed $\mathrm{EB} 1^{\mathrm{K} 89 \mathrm{E}}$ using the V5 affinity tag revealed a diffuse phenotype in comparison with V5-tagged wild-type EB1 (Figure 6A). Surface biotinylation of HeLa cells stably expressing Cx43 and transiently transfected with $\mathrm{EB} 1^{\mathrm{K} 89 \mathrm{E}}$, grown in the presence of the endocytosis inhibitor Dynasore, revealed a significant drop in $\mathrm{Cx} 43$ levels at the plasma membrane in comparison with those expressing wild-type EB1 (Figure 6B). These data indicate that EB1 displacement during oxidative stress is a causative lesion in the perturbation of microtubule-dependent $\mathrm{Cx} 43$ forward trafficking to the plasma membrane.

Oxidative stress limits gap junction development in the zebrafish heart, slowing conduction. To determine, as a proof of concept, whether oxidative stress in vivo could directly induce slowed ventricular excitation with a reduction of cell-cell coupling, a zebrafish transgenic line expressing EGFP-tagged connexin in the heart was generated and exposed at 24 hours following fertilization ( $24 \mathrm{hpf}$ ) to $100 \mathrm{~nm}$ $\mathrm{H}_{2} \mathrm{O}_{2}$ or normal media. Results shown in Figure 7A indicate that oxidative stress limits localization of connexins to the plasma membrane and enriches cytoplasmic content of the channel but does not appear to affect adherens junction formation. Using a transgenic zebrafish line that expresses the intracellular calcium reporter gCaMP (47) in the heart, we were able to optically map in vivo the excitation process in $\mathrm{H}_{2} \mathrm{O}_{2}$-treated fish (48). Studies revealed that oxidative stress results in slowed and heterogeneous ventricular activation (Figure 7B and Supplemental Videos 8 and 9). With oxidative stress, peak conduction velocities were less than $10 \mathrm{~cm} / \mathrm{s}$ and most velocities were less than $5 \mathrm{~cm} / \mathrm{s}$ (Figure 7C), compared with $34 \mathrm{~cm} / \mathrm{s}$ in controls. These severely slowed conduction times are consistent with a loss of functional gap junctions rather than a reduction in excitatory membrane current (1). 
A

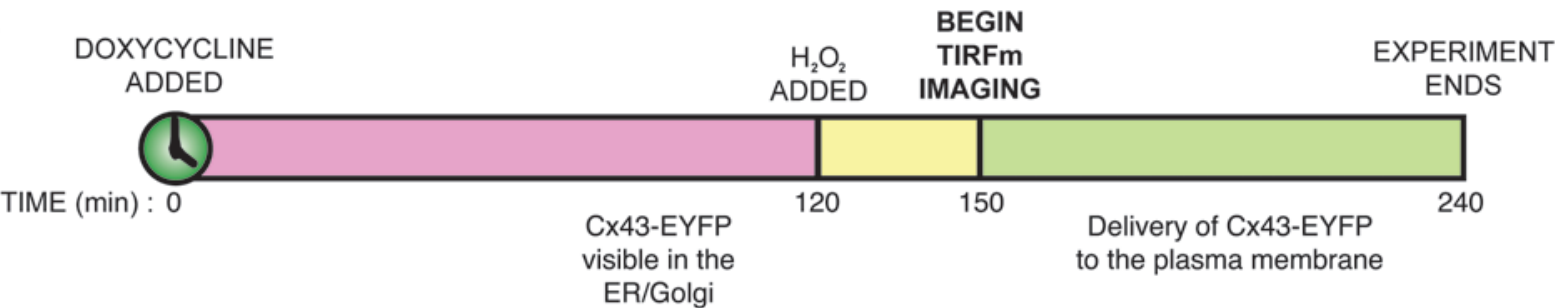

B

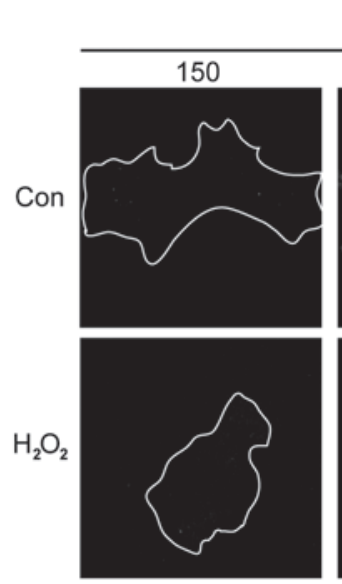
Time (min)
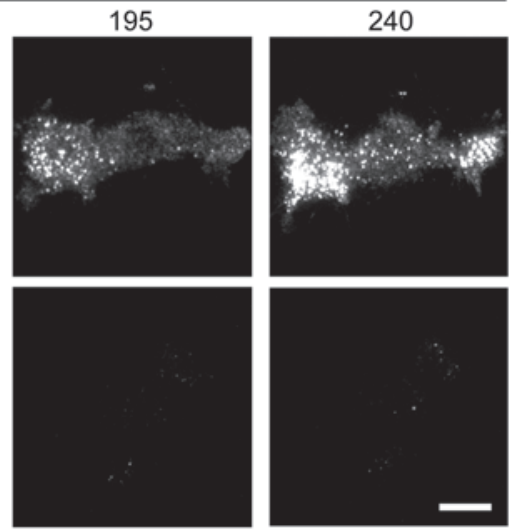

D

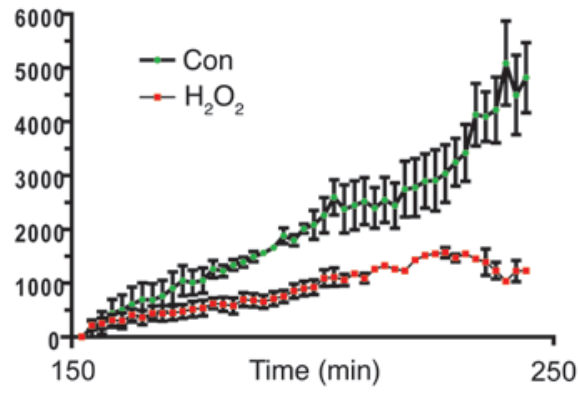

C
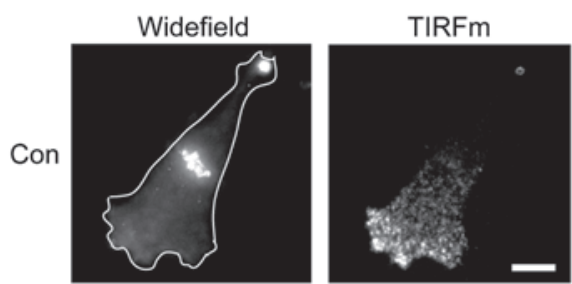

$\mathrm{H}_{2} \mathrm{O}_{2}$
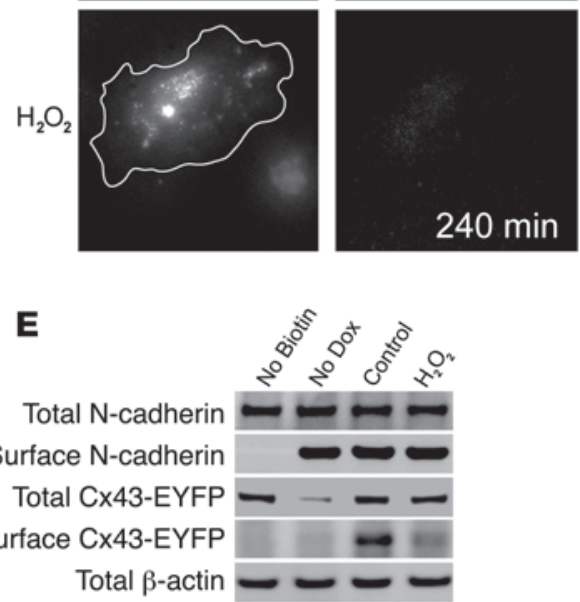

Figure 5

Forward trafficking of $\mathrm{Cx} 43$ to the plasma membrane is reduced during oxidative stress. (A) Timeline of Tet-inducible Cx43-EYFP trafficking assay. A tetracycline-inducible clonal HeLa cell line expressing Cx43-EYFP was induced with $2 \mu \mathrm{g} / \mathrm{ml}$ doxycycline 2.5 hours prior to imaging with TIRFm in the presence or absence of $200 \mu \mathrm{M} \mathrm{H}_{2} \mathrm{O}_{2}$, which was added 30 minutes prior to imaging. (B) TIRFm visualization of Cx43-EYFP delivery. TIRFm detection of Cx43-EYFP at 150, 195, and 240 minutes after the addition of doxycycline in the presence or absence of $\mathrm{H}_{2} \mathrm{O}_{2}$. White lines outline cell cortex. (C) Comparison of widefield epifluorescence and TIRFm detection of Cx43-EYFP at 240 minutes after the addition of doxycycline, showing that cells contain comparable levels of Cx43-EYFP. (D) Quantification of TIRFm-detectable Cx43-EYFP surface intensity. Error bars represent SEM. (E) Total and surface N-cadherin and Cx43-EYFP levels following total surface protein biotinylation and pulldown through neutravidin. Input lysates and pulldowns of biotinylated surface proteins were subjected to SDS-PAGE on the same gel. Original magnification, $\times 100$. Scale bars: $10 \mu \mathrm{m}$. Values represent mean \pm SEM.

\section{Discussion}

The life cycle of $\mathrm{Cx} 43$ protein can be subdivided into formation and delivery to the plasma membrane, existence within the plasma membrane, and internalization. Much has been learned about the regulation and movement of cardiac $\mathrm{Cx} 43$ once the protein is in the membrane $(18,37,49)$, as well as regarding its internalization under normal $(41,50)$ and stressed conditions $(4)$. It is well established that microtubules deliver $\mathrm{Cx} 43$ to the plasma membrane (17, 19). More recently, we found that microtubule delivery could be targeted directly to adherens junctions through interaction between the microtubule plus end protein EB1 and adherens junction structures (24). Here, we asked whether cardiac stress conditions affect the forward trafficking and delivery of $\mathrm{Cx} 43$. We made the surprising discovery that EB1 is displaced from the plus end of microtubules during oxidative stress (Figure 3). Displacement of EB1 alters microtubule growth patterns (Figure 4C and Figure 6A) and is sufficient to reduce forward delivery of $\mathrm{Cx} 43$ to the plasma membrane (Figure 5 and Figure 6B). Altered EB1 localization and complexing during stress occurs in HeLa cell lines (Figures 3-6), primary mouse ventricular cardiomyocytes (Figure 2E and Supplemental Figure 5), mouse heart (Figure 2), and human heart (Figure 1). Impaired forward trafficking was confirmed to be involved in stress-induced decreased surface expression of $\mathrm{Cx} 43$ as assayed by surface biotinylation in the presence of endocytosis (retrograde trafficking) inhi- 
A
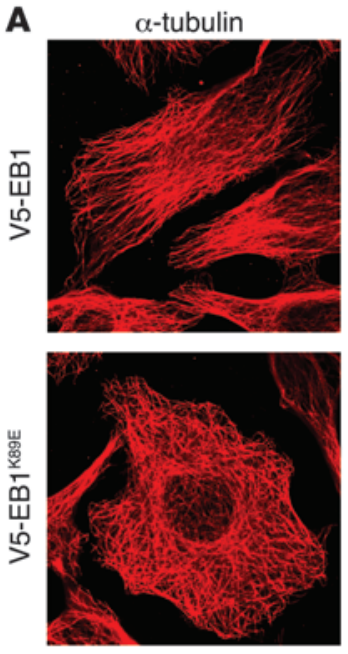

V5
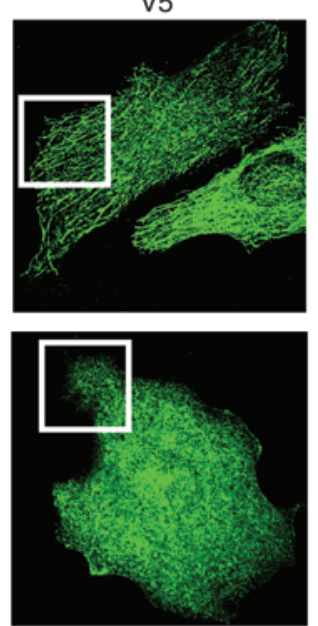

Overlay
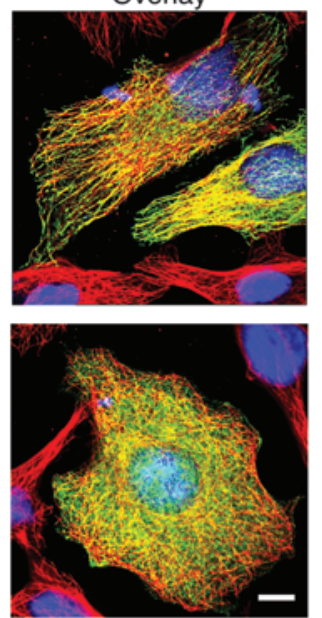

B
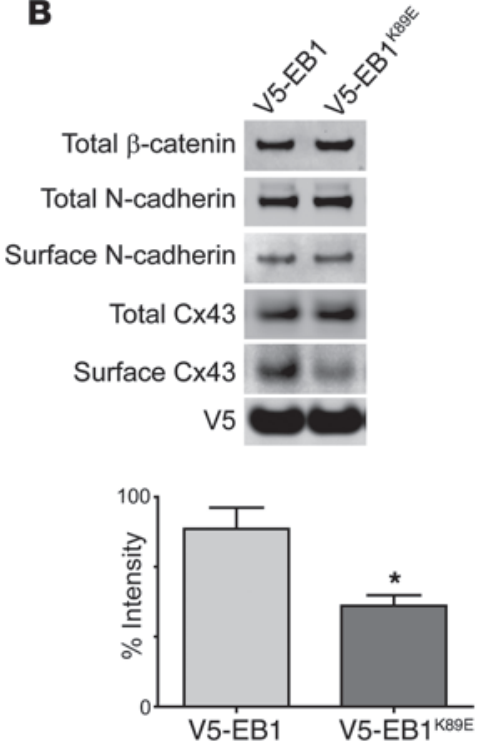

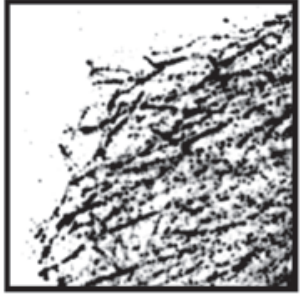

V5-EB1

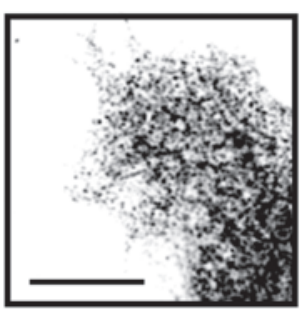

V5-EB1 ${ }^{\text {K89E }}$

\section{Figure 6}

EB1 displacement alone is sufficient to lower Cx43 levels at the plasma membrane. A point mutation (K89E) was introduced within the tubulin-binding domain of EB1, and a stable HeLa clonal cell line expressing Cx43 was transfected with either N-terminal V5-tagged wild-type EB1 or EB1K89E. (A) Overexpression of EB1 and EB1 $189 \mathrm{E}$ in HeLa cells. Immunofluorescence labeling of $\alpha$-tubulin in red and V5 tag in green with overlay images including the nuclear counterstain DAPI in blue. Enlarged regions were inverted and presented in grayscale to facilitate visualization of protein localization. Original magnification, $\times 60$. Scale bar: $10 \mu \mathrm{m}$. (B) Surface biotinylation was performed, and input lysates and pulldowns of biotinylated surface proteins were subjected to SDS-PAGE on the same gel. Endocytosis was inhibited using $80 \mu \mathrm{M}$ Dynasore. Results are representative of 3 separate experiments. Statistical analysis was performed using the Student's unpaired $t$ test. Error bars represent mean \pm SEM. ${ }^{*} P<0.05$.

bition (Figure 2E, Figure 6, and Supplemental Figure 3). We also found that oxidative stress reduces localization of connexin to the plasma membrane in zebrafish hearts in which conduction slowing was confirmed by optical mapping (Figure 7).

The oxidative stress component of heart disease has been well described (28-31), and we chose to use it as a reproducible, wellcontrolled insult, as it is conveniently applicable in the laboratory setting. In fact, ischemia-reperfusion injury generates levels of oxidative stress similar to $10 \mu \mathrm{m} \mathrm{H}_{2} \mathrm{O}_{2}$ in Langendorff-perfused adult mouse heart (Figure 2A). Recent reports indicate an increase in the understanding of the association between oxidative stress and ischemic pathophysiology, such as activation of CamKII through direct protein oxidation (51) and inhibition of sodium channels (52). However, despite an increased appreciation of the impact of oxidative stress, we hesitate to conclude that such stress is the exclusive regulator of decreased cell-cell coupling during myocardial ischemia. Rather, the major emphasis of our findings are that the forward trafficking process of $\mathrm{Cx} 43$ delivery to intercalated discs is disrupted by at least the oxidative stress component of chronic ischemia and ischemia-reperfusion injury.

Most cardiac ion channels have a rapid turnover on the order of hours. For example, the $\mathrm{Cx} 43$ protein has a half-life of 1.3 hours in the heart (36), and fluorescent recovery after photobleaching experi- ments indicate that delivery to gap junction plaques can occur within minutes $(19,24)$. With full cycles of turnover occurring several times per day, forward trafficking of de novo channel is a major opportunity for regulation, and its perturbation can therefore quickly manifest as decreased cell-cell coupling conductance. While the forward delivery apparatus is likely to have specific characteristics for each ion channel and microdomain, a generalized model is starting to emerge. Post-Golgi transport of channels along microtubules is probably a common means of delivery for de novo channels. Specificity can be achieved by microtubule plus end tracking proteins such as EB1 and membrane scaffolding proteins such as the cadherin-based adherens junction structure (24). In this study, our findings in cryosections of human tissue highly supported the idea that EB1 localizes at the intercalated discs of adult human heart and is displaced in ischemic heart disease (Figure 1C). A similar scaffolding protein target model exists between ankyrin and both sodium channels (53) and sodium transporters (54). It is exciting to report that when oxidative stress displaces EB1 from microtubules, $\mathrm{Cx} 43$ delivery is impaired. To our knowledge our findings are the first to suggest that a cardiac ion channel forward delivery apparatus can be disrupted by acquired heart disease such as ischemic heart disease, and that EB1 displacement and slowed microtubule dynamics are important aspects of arrhythmogenic downregulation of gap junction coupling. 
A
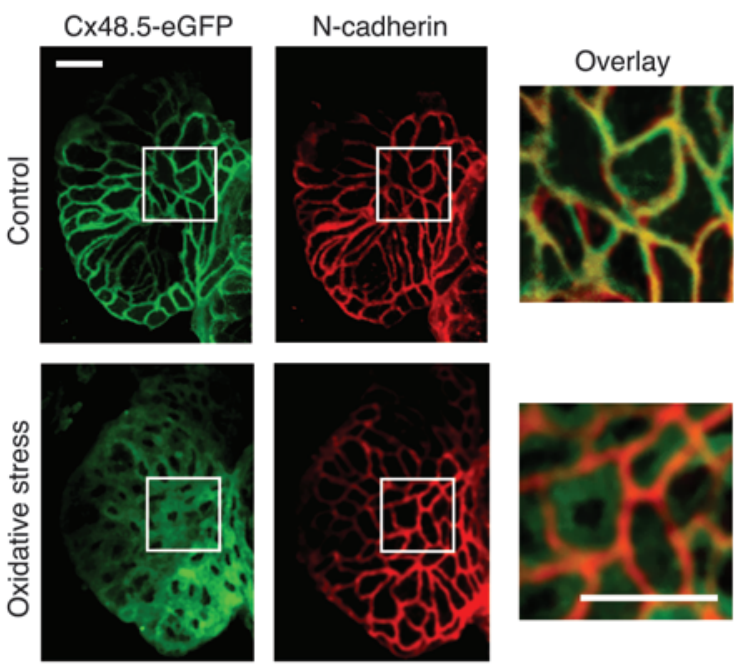

B

\section{Control Oxidative stress}
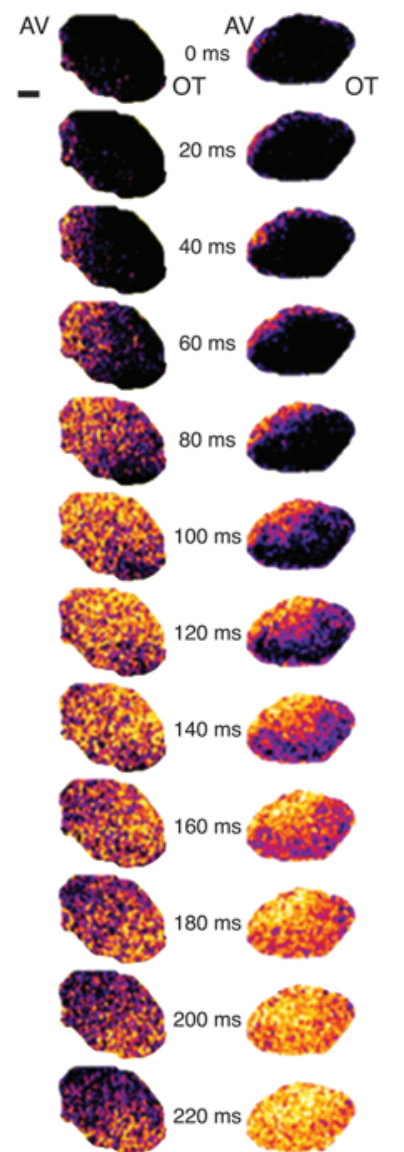

D
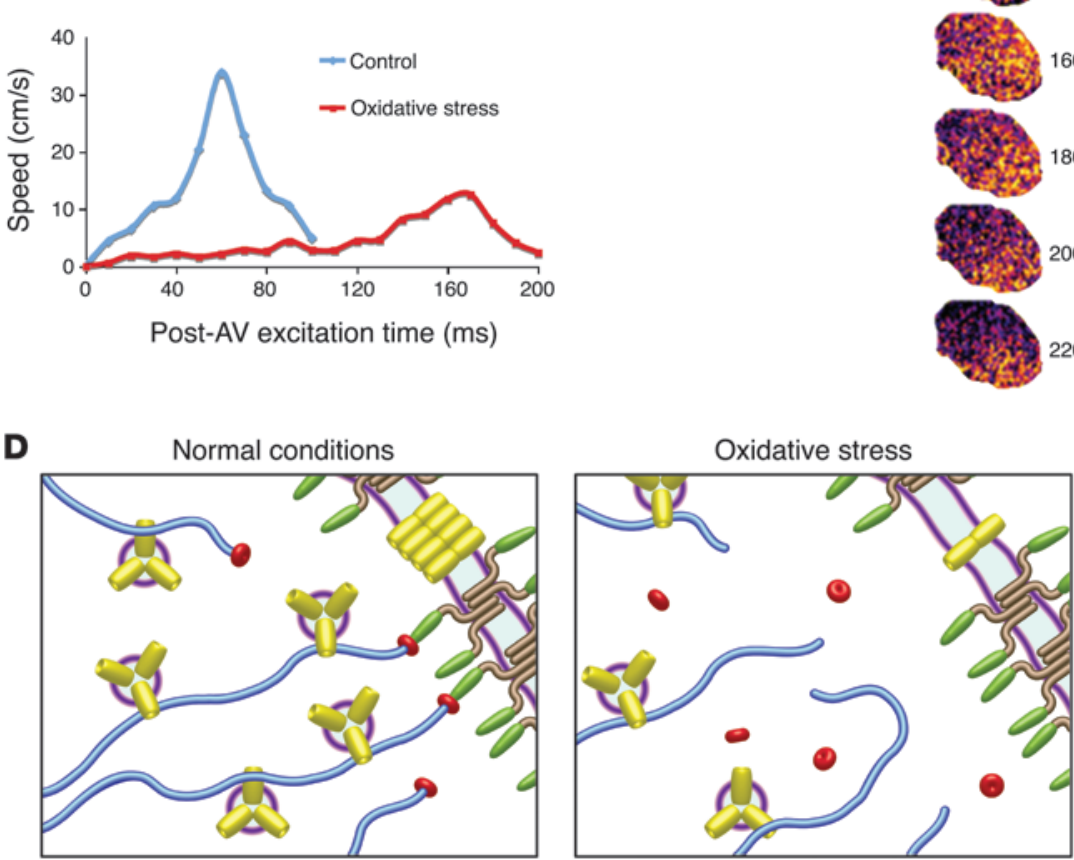

Oxidative stress

\section{Figure 7}

Oxidative stress decreases gap junction coupling, slowing cardiac excitation in the zebrafish embryo. (A) Zebrafish transgenic connexin and $\mathrm{N}$-cadherin expression. Three-dimensional reconstruction by $\times 40$ confocal microscopy at $48-60 \mathrm{hpf}$ of $T$ g(cm/c2:Cx48.5-EGFP)s882 zebrafish hearts after 24 hours of control medium with or without $100 \mathrm{nM} \mathrm{H}_{2} \mathrm{O}_{2}$. Cx48.5-EGFP is presented in green and $\mathrm{N}$-cadherin in red. Enlargement of the white boxes, presented as overlay images, shows cytoplasmic Cx48.5-EGFP during oxidative stress. (B) Optical mapping with pseudocolor of calcium transients in the ventricles of separate $\mathrm{Tg}(\mathrm{cmlc2}: \mathrm{gCaMP})^{8878}$ hearts exposed to normal or oxidative stress conditions. The signal first crossed the $\mathrm{AV}$ node at $t=0$. AV, atrioventricular node; OT, outflow tract. (C) Conduction velocity from the leading edge of the excitation wavefronts obtained from isochronal maps of the data in B. Original magnification, $\times 40$. Scale bar: $20 \mu \mathrm{m}$. (D) Schematic representation of the proposed mechanism of failed $\mathrm{Cx} 43$ delivery during oxidative stress.

Multiple related forms of altered gap junction regulation exist. In ischemic heart disease, immunodetectable $\mathrm{Cx} 43$ is lateralized to non-intercalated disc sarcolemma and scattered throughout cardiomyocytes bordering infarct zones (6). We also observed some lateral localization of $\mathrm{Cx} 43$ in ischemic human and stressed mouse tissue (Figure 1A and Figure 2B). The mechanisms of lateralization may be related to a c-Src-mediated reduction in $\mathrm{Cx} 43 / \mathrm{ZO}-1$ interaction that "unhooks" gap junction structures from the intercalated disc $(38,49,55)$. Localization of $\mathrm{Cx} 43$ away from the intercalated disc provides a substrate for reentrant ventricular tachy- 
cardia (7). Simple loss of $\mathrm{Cx} 43$ at the intercalated disc can also be arrhythmogenic. Computer modeling studies have revealed that losses in gap junction coupling alone can lead to arrythmogenic conduction slowing $(1,56)$. Syndromes such as arrythmogenic right ventricular cardiomyopathy (ARVC) have a pathophysiology in which $\mathrm{Cx} 43$ does not appear to be lateralized but occurs in lower amounts at intercalated discs (57). The loss of gap junction coupling in ARVC and related syndromes is believed to be the primary lesion contributing to arrhythmogenesis as it precedes other structural remodeling in the myocardium (58-60). Moreover, studies in transgenic mice in which $\mathrm{Cx} 43$ levels have been conditionally reduced consistently reveal conduction slowing and arrhythmogenic susceptibility $(61,62)$. Reduction of $\mathrm{Cx} 43$ at the intercalated disc can also be due to internalization secondary to the altered metabolic conditions of ischemic substrate $(4,63)$. In sum, lateralization and internalization are important features of gap junction remodeling and, together with forward trafficking, likely combine for exquisite regulation of $\mathrm{Cx} 43$ at the intercalated disc.

The data in this study also indicate that the cytoskeleton delivery apparatus may be a focus for therapeutic interventions aimed at the preservation and enhancement of cardiac gap junction coupling. Future elucidation of the mechanisms by which EB1 is displaced from microtubule plus ends by oxidative stress could provide a means to rescue EB1 displacement and preserve $\mathrm{Cx} 43$ delivery to the intercalated disc. Therefore, interventions preserving EB1 binding to microtubule plus ends could safeguard myocardial function through protection of electrical coupling following or during cardiac insult.

\section{Methods}

Mice. Timed pregnant female and 8- to 10-week-old male C57BL/6 mice were obtained from Charles River Laboratories and maintained under sterile barrier conditions. All procedures were reviewed and approved by the University of California IACUC.

Molecular biology. Human Cx43 and human EB1 cDNAs were obtained from Open Biosystems and cloned into pDONR/Zeo (Invitrogen) using Gateway BP cloning to generate entry (ENTR) clones. Cx43 and EB1 genes were subsequently inserted into pDest-EGFP-N1, pDest-TRE-Tight (converted vectors originally from Clontech), pcDNA3.2-V5-Dest, pcDNA3.1/ $\mathrm{n}-\mathrm{V} 5$, and pLenti6.3-V5-Dest (Invitrogen) by Gateway LR cloning. Human $\mathrm{Cx} 43$ (with a stop codon) was also inserted by gateway cloning into pLenti6.3/V5-Dest. The EB1-K89E point mutation was generated using the Quickchange II site-directed mutagenesis kit (Stratagene) according to the manufacturer's instructions and pENTR/Zeo-EB1 as a template (forward primer: AGAATGGGTGTTGACGAAATAATTCCTGTGGAC; reverse primer: GTCCACAGGAATTATTTCGTCAACACCCATTCT). EB1 was inserted into pLVX-AcGFP-N1 (Clontech) by traditional restriction cloning.

Cell culture. HeLa cells (ATCC) were maintained in DMEM (Invitrogen) supplemented with 10\% FBS (Invitrogen) and $100 \mu \mathrm{g} / \mathrm{ml}$ Normocin (Amaxa). Primary mouse neonatal cardiomyocytes were isolated from $\mathrm{p} 3$ C57BL/6 mice and maintained in F12/DMEM 50/50 (Invitrogen) supplemented with $2 \%$ FBS, insulin-transferrin-sodium selenite media supplement, $10 \mu \mathrm{M}$ BrdU, $20 \mu \mathrm{M}$ cytosine $\beta$-D-arabinofuranoside (Sigma-Aldrich), and $100 \mu \mathrm{g} / \mathrm{ml}$ primocin (Amaxa Biosystems). Cells were maintained in a humidified atmosphere of $5 \% \mathrm{CO}_{2}$ at $37^{\circ} \mathrm{C}$. Unless otherwise stated in the figure legends, cells were seeded at a density of $7 \times 10^{4}$ cells $/ \mathrm{cm}^{2}$ and allowed to adhere overnight. Cells were treated with $200 \mu \mathrm{M} \mathrm{H}_{2} \mathrm{O}_{2}$ (Sigma-Aldrich) in fully supplemented medium prior to fixation.

Generation of pLenti6.3-Cx43 clonal HeLa cell line. Lentivirus was produced from pLenti6.3-Cx43 according to the manufacturer's (Invitrogen) instruc- tions and used to infect HeLa cells previously plated in 6-well dishes in the presence of $4 \mu \mathrm{g} / \mathrm{ml}$ hexadimethrine bromide (Sigma-Aldrich). Medium was changed the following morning, and cells were split into $100-\mathrm{mm}$ dishes at a dilution of 1:40 in the presence of blasticidin $(10 \mu \mathrm{g} / \mathrm{ml})$. Medium was changed every 2 days and healthy colonies were picked using trypsin cloning cylinders (Scienceware), expanded, and screened for expression by Western blotting and immunofluorescence.

EB1 and $\alpha$-tubulin immunofluorescence. For EB1 and $\alpha$-tubulin staining, cells were fixed for 5 minutes at $-20^{\circ} \mathrm{C}$ in $100 \%$ methanol. Three PBS washes were performed, and cells were permeabilized for 4 minutes using $0.1 \%$ Triton X-100 (Sigma-Aldrich) in PBS. Cells were then washed and blocked for 1 hour at room temperature in 5\% normal goat serum (NGS; Invitrogen) before addition of primary antibodies. Mouse monoclonal antibodies to EB1 (1:500) were obtained from BD Biosciences, and rat monoclonal antibodies to $\alpha$-tubulin (1:500) were from Abcam. Cells were incubated with primary antibodies diluted in 5\% NGS in PBS for 1 hour at room temperature. Following several PBS washes, cells were incubated for an additional hour with goat secondary antibodies conjugated to Alexa Fluor 488 (Invitrogen), or CY3 (Jackson Laboratories) and TO-PRO-3 nuclear counterstain (Invitrogen). Cells were washed with PBS, washed briefly with $\mathrm{dH}_{2} \mathrm{O}$, and coverslips were mounted using ProLong gold antifade reagent (Invitrogen). Slides were allowed to dry overnight and imaged using a Nikon Ti microscope with a $\times 60 / 1.49$ Apo TIRF objective, Yokogowa CSU-X1 spinning disk confocal unit with 486-, 561-, and 647-nm DPSS laser source, and Coolsnap $\mathrm{HQ}^{2}$ camera controlled by NIS Elements software (Nikon). Additional image processing and analysis was performed using ImageJ (NIH). Equal thresholds were set for individual images, and EB1 comet length was measured blind using the ImageJ measure function. Only those comets approaching the cell periphery and entirely within the focal plane were measured. At least 15 comets/cell were measured for 5 cells within each condition.

Surface protein biotinylation. pLenti6.3-Cx43 HeLa cells were seeded in $100-\mathrm{mm}$ dishes and allowed to adhere overnight. Cells were incubated for 16 hours in the presence or absence of $200 \mu \mathrm{M} \mathrm{H}_{2} \mathrm{O}_{2}$. Dynasore $(80 \mu \mathrm{M}$; Sigma-Aldrich) was added 1 hour prior to $\mathrm{H}_{2} \mathrm{O}_{2}$, and DMSO was added as vehicle to control cells. Freshly isolated primary adult mouse ventricular cardiomyocytes were seeded in fully supplemented Cardiac Myocyte Medium (CMM; ScienCell) onto 600-mm dishes that had been coated overnight with $2 \mathrm{mg} / \mathrm{ml}$ laminin (Invitrogen). Cells were allowed to adhere for 1 hour before exposure to $10 \mu \mathrm{M} \mathrm{H}_{2} \mathrm{O}_{2}$ or not diluted in fresh CMM in the presence or absence of $40 \mu \mathrm{M}$ Dynasore for 4 hours. Surface proteins were biotinylated following 2 washes with ice-cold PBS by incubating cells for 20 minutes at $4^{\circ} \mathrm{C}$ with EZ-link Sulfo-NHS-SS-Biotin (Pierce Biotechnology) at a concentration of $1 \mathrm{mg} / \mathrm{ml}$ in PBS. Cells were washed in icecold PBS and incubated twice for 5 minutes each time in PBS containing $100 \mathrm{mM}$ glycine to remove unbound biotin. After a further 3 washes in ice-cold PBS, cells were lysed using 200- $\mu$ RIPA buffer (50 mM Tris pH 7.4, $150 \mathrm{mM} \mathrm{NaCl}, 1 \mathrm{mM}$ EDTA, 1\% Triton X-100, 1\% sodium deoxycholate, $2 \mathrm{mM} \mathrm{NaF}, 200 \mu \mathrm{M} \mathrm{Na}_{3} \mathrm{VO}_{4}$ ) supplemented with Complete Mini Protease Inhibitor Cocktail (Roche). Cells were scraped into RIPA buffer, and lysates were sonicated using a Microson ultrasonic cell disruptor (Misonex) before centrifugation at $10,000 \mathrm{~g}$ for 20 minutes at $4{ }^{\circ} \mathrm{C}$. Protein concentration in the clarified lysates was determined using the BioRad $\mathrm{D}_{\mathrm{C}}$ Protein Assay and normalized. A total of $1 \mathrm{mg}$ of protein from each condition was incubated in RIPA buffer with $25 \mu \mathrm{l}$ of Ultralink Immobilized NeutrAvidin slurry (Pierce Biotechnology) overnight at $4^{\circ} \mathrm{C}$ with rotation. Tubes were centrifuged for 1 minute at $300 \mathrm{~g}$ and allowed to settle for 2 minutes before the supernatant was removed. RIPA buffer $(1 \mathrm{ml})$ was added to each tube, and tubes were inverted to mix and spun down again at $300 \mathrm{~g}$. This process was repeated 4 times before the addition of $20 \mu \mathrm{l} 2 \mathrm{X}$ NuPAGE sample buffer 
(Invitrogen) supplemented with $100 \mathrm{mM}$ DTT (Sigma-Aldrich). Samples were heated for 10 minutes at $70^{\circ} \mathrm{C}$ prior to subjection to SDS-PAGE electrophoresis and Western blotting (see below).

Western blotting. After heating to $70^{\circ} \mathrm{C}$ for 10 minutes, samples were cooled to room temperature and subjected to SDS-PAGE electrophoresis using NuPAGE Bis-Tris gels and MES (Invitrogen) buffer according to the manufacturer's instructions. Gels were transferred to FluoroTrans PVDF membranes (Pall), which were subsequently fixed by soaking in methanol and air drying before rewetting with methanol and blocking for 1 hour at room temperature in $5 \%$ nonfat milk (Carnation) in TNT buffer $(0.1 \%$ Tween 20, $150 \mathrm{mM} \mathrm{NaCl}, 50 \mathrm{mM}$ Tris $\mathrm{pH}$ 8.0). Membranes were then incubated overnight with primary antibodies diluted in $5 \%$ milk in TNT. Primary antibodies used were rabbit anti-Cx43 (1:4,000; Sigma-Aldrich), rabbit anti-N-cadherin (1:4,000; Abcam), rabbit anti- $\beta$-catenin $(1: 2,000$; Abcam), rabbit anti-EB1 (1:4,000; Sigma-Aldrich), rat anti- $\alpha$-tubulin (1:1,000; Abcam), rabbit anti-V5 (1:3,000; Sigma-Aldrich), mouse anti$\beta$-actin (1:3,000; Sigma-Aldrich), and mouse anti-GAPDH (1:3,000; Abcam). Membranes were washed 5 times before incubation for 1 hour at room temperature with secondary antibodies diluted in 5\% milk TNT. Goat secondary antibodies conjugated to Alexa Fluor 555 and 633 were used at a dilution of 1:1,000. Following incubation with secondary antibody, membranes were washed 5 times, soaked in methanol, and allowed to air dry. Membranes were imaged using the Versadoc MP 4000 fluorescent western detection system (BioRad).

TIRF microscopy. Imaging was carried out using a Nikon TE-2000E inverted microscope with a $\times 100 / 1.49$ Apo TIRF objective and through-the-objective TIRF illumination using a 488-nm argon laser for EGFP visualization and a 514-nm laser for EYFP. The photometrics Cascade II 512 camera was used for acquisition of all TIRFm studies. Cells were maintained in HBSS (Invitrogen) plus $10 \% \mathrm{FBS}$ at $37^{\circ} \mathrm{C}$ for all live cell imaging studies. All TIRF image processing was performed with ImageJ software (NIH).

Assessing the effect of oxidative stress on the interaction of EB1-EGFP with the plasma membrane. Glass-bottomed 35-mm dishes (Mattek) were coated with $\mathrm{N}$-cadherin as previously described (24). HeLa cells were plated in complete DMEM and allowed to adhere overnight. Cells were transfected with pDest-EB1-EGFP-N1 using $2 \mu \mathrm{g}$ DNA/dish and Fugene 6. For primary neonatal mouse ventricular cardiomyocytes, dishes were coated with $5 \mu \mathrm{g} / \mathrm{ml}$ fibronectin and $0.02 \%$ gelatin for 4 hours prior to $\mathrm{N}$-cadherin attachment. Lentivirus was produced using pLVX-EB1-AcGFP according to the manufacturer's instructions (Clontech and Invitrogen), and cardiomyocytes were infected overnight in the presence of $4 \mu \mathrm{g} / \mathrm{ml}$ hexadimethrine bromide. Lentivirally transduced cardiomyocytes were imaged 72 hours after infection. Medium was changed to HBSS with $10 \%$ FBS (2\% for neonatal cardiomyocytes) and epifluorescence used to select cells expressing similar amounts of EB1-EGFP 24 hours after transfection. TIRFm time lapse sequences of 2 minutes were acquired at an exposure of $200 \mathrm{~ms}$ per image and rate of 30 frames/minute. Acquisitions were performed every 15 minutes for 45 minutes under normal conditions, $\mathrm{H}_{2} \mathrm{O}_{2}$ was added to the HBSS to a final concentration of $200 \mu \mathrm{M}$, and 3 more acquisitions were performed at 15 -minute intervals. At this point, dishes were gently washed 4 times with warm HBSS containing $10 \%$ FBS, and a final 3 acquisitions were taken to assess recovery over a 45 -minute period. Comet density was determined by first defining a region of interest via a freehand tool on ImageJ, then background subtraction was performed with a 10-pixel rolling ball radius and thresholds were assigned to images. Comets were defined as 2 or more contiguous pixels identified by the particle analyzer function.

Live-cell spinning disc confocal microscopy of $\alpha$-tubulin-EGFP. HeLa cells were plated and transfected with pEGFP-N1- $\alpha$-tubulin as described above. Twenty-four hours after transfection, cells were exposed to normal conditions or $200 \mu \mathrm{M} \mathrm{H}_{2} \mathrm{O}_{2}$ for 2 hours, after which dishes were imaged using a Nikon Ti inverted microscope, Yokogowa CSU-X1 spinning disk confocal unit with 486-nm DPSS laser source, and a Cascade II 512 camera (Photometrics). Images were acquired every 5 seconds (400-ms exposure) for a time span of 5 minutes. Only microtubules that were observed growing and/or shrinking near the cell periphery for several minutes were tracked. The position of each microtubule end was tracked over time using ImageJ (NIH). Images were inverted, background subtracted, and contrast enhanced. The ImageJ plug-in MTrackJ (http://www.imagescience. org/meijering/software/mtrackj/) was used to manually track individual microtubule plus ends. Microtubule dynamics and events were classified as previously reported (64) with an optical resolution limit of $0.16 \mu \mathrm{m}$ and analyzed in Excel (Microsoft) using a custom-written macro. The number of microtubules directly approaching the cell cortex (within $3 \mu \mathrm{m}$ of cell edge) was determined for each 5 -minute acquisition. Data were compiled from 3 separate experiments to a total of 9 cells per condition.

Generation of tetracycline-inducible Cx43-EYFP HeLa cell clones. HeLa Tet-ON cells were purchased from Clontech and maintained in fully supplemented DMEM containing $500 \mu \mathrm{g} / \mathrm{ml}$ Geneticin (Invitrogen). Cells were plated into $100-\mathrm{mm}$ dishes at a density of $10^{6} \mathrm{cells} /$ dish and allowed to adhere overnight. The next day, the cells were transfected with pDest-TRE-Cx43EYFP and a linear Hygromycin selection marker (Clontech) according to the manufacturer's instructions. Forty-eight hours after transfection, cells were trypsinized and plated into fresh dishes at a dilution of 1:40 in fully supplemented medium containing $500 \mu \mathrm{g} / \mathrm{ml}$ Geneticin and $200 \mu \mathrm{g} / \mathrm{ml}$ Hygromycin. Dishes were monitored and when large healthy colonies had developed, clones were picked using trypsin cloning cylinders, expanded, and screened for tightly regulated expression.

Real-time detection of CX43-EYFP delivery to the plasma membrane using TIRF microscopy. Glass-bottomed dishes $(35 \mathrm{~mm})$ were coated with $\mathrm{N}$-cadherin as previously described (24) before clonal HeLa Tet-ON Cx43-EYFP cells were seeded at a concentration of $10^{5}$ cells/dish and allowed to adhere overnight. Cells were washed once with PBS and induced with $2 \mu \mathrm{g} / \mathrm{ml}$ doxycycline (Sigma-Aldrich) in HBSS (Invitrogen) without phenol red supplemented with $10 \%$ FBS. Dishes were moved to the heated chamber of a Nikon Eclipse TE2000-E microscope and left undisturbed for 120 minutes. At this point, fresh supplemented HBSS containing doxycycline with or without $\mathrm{H}_{2} \mathrm{O}_{2}$ at a final concentration of $200 \mu \mathrm{M}$ was added. After $30 \mathrm{~min}-$ utes ( $t=150$ minutes after induction), it was possible to see Cx43-EYFP in the ER and Golgi by epifluorescent detection. Healthy cells were selected, and TIRF microcopy was used to acquire 90-minute time-lapse sequences, with images acquired 2 minutes apart for 200 milliseconds per image. For quantification, ImageJ software was used to determine fluorescence intensity within a region of interest defined by the cell periphery.

Detection of CX43-EYFP delivery to the plasma membrane by biotinylation. HeLa Tet-ON Cx43-EYFP cells were seeded in 100-mm dishes at a concentration of $10^{6}$ cells/dish and allowed to adhere overnight. Fresh medium containing $2 \mu \mathrm{g} / \mathrm{ml}$ doxycycline was added to the cells 120 minutes prior to incubation with $\mathrm{H}_{2} \mathrm{O}_{2}$ for 120 minutes at $37^{\circ} \mathrm{C}$.

Zebrafish husbandry and oxidative stress induction. Zebrafish were raised under standard laboratory conditions at $28^{\circ} \mathrm{C}$. The following transgenic lines were used: $\operatorname{Tg}(c m l c 2: c x 48.5-E G F P)^{s 82}$ and $\operatorname{Tg}(c m l c 2: g C a M P)^{s 878}(48,65)$. The cmlc2:C $x 48.5-E G F P$ construct was created by cloning a 900-bp fragment of the $\mathrm{cmlc2}$ promoter upstream of the full-length cDNA zebrafish Cx48.5 fused to EGFP. Linearized DNA (200 pg) was injected into 1 cellstage embryos, and we selected individual transgenic carrier adults by screening for fluorescent progeny. Three $T g(c m l c 2: C x 48.5-E G F P)^{s 882}$ founders were recovered with nearly identical expression patterns and levels. In order to induce oxidative stress on zebrafish embryos, $\mathrm{H}_{2} \mathrm{O}_{2}$ was serially titrated from $1 \mathrm{nM}$ to $200 \mu \mathrm{M}$ in egg water medium. Embryos were treated at $24 \mathrm{hpf}$ and analyzed at $48-60 \mathrm{hpf}$. 
Zebrafish immunohistochemistry and confocal microscopy. Immunohistochemistry and confocal microscopy were performed as previously described (48). Affinity-purified zebrafish cadherin 2 antibody (66) was used at a dilution of 1:80.

Zebrafish optical mapping by widefield epifluorescence. Using the $\mathrm{Tg}(\mathrm{cmlc2}$ : $g C a M P)^{s 878}$ line, optical mapping was performed on individual embryos at 48-60 hpf as previously described (48). Briefly, the upstroke of the calcium transient is registered as the activation point of the cell, which is appropriate if one assumes the same phase delay between voltage activation and calcium transient through the ventricle. Isochronal maps were drawn, and the activation time between the isochrones was recorded for a measurement of conduction velocity.

Langendorff-perfused mouse heart preparation. Male C57BL/ 6 mice were anesthetized with isoflurane and injected with heparin (50 IU i.p.). After cervical dislocation, hearts were removed quickly by a midsternal incision and placed into ice-cold modified Krebs-Henseleit (K-H) solution. Under a dissecting microscope, the aortic opening was immediately cannulated and tied on a 23-gauge stainless steel blunt needle. The heart was attached to a Langendorff apparatus (ADInstruments) and perfused through the aorta at a constant rate of $4 \mathrm{ml} / \mathrm{min}$ with a modified $\mathrm{pH} 7.4 \mathrm{~K}-\mathrm{H}$ buffer of the following composition (in mM): $\mathrm{NaCl} 118, \mathrm{KCl} 4.7, \mathrm{CaCl}_{2} . \mathrm{H}_{2} \mathrm{O} 2.5, \mathrm{MgCl}_{2} .7 \mathrm{H}_{2} \mathrm{O}$ 1.2, $\mathrm{NaHCO}_{3} 24, \mathrm{KH}_{2} \mathrm{PO}_{4} 1.2$, glucose 11, EDTA 0.5. The K-H solution was prefiltered by a microfilter $(0.2-\mu \mathrm{m}$ diameter; Nalgene) and constantly gassed with $95 \% \mathrm{O}_{2} / 5 \% \mathrm{CO}_{2}$. Perfusion medium was passed through water-jacketed tubing and cylinders, and the temperature was maintained at $37^{\circ} \mathrm{C}$ with a temperature-controlled circulating water bath. The hearts were allowed to equilibrate for 10 minutes to achieve a steady state before they were subjected to 30 minutes of global ischemia, followed by 60 minutes of reperfusion. Control hearts were perfused continuously throughout the protocol. Pacing was used (typically at $150 \%$ of threshold: $500 \mathrm{~mA}$, Stimulus Isolator; ADInstruments) during the whole experimental protocol except for periods of ischemia. During no-flow ischemia, the heart was immersed in warm $\mathrm{K}-\mathrm{H}$ buffer in order to maintain warmth and moisture. Immediately after Langendorff procedure, hearts were placed in cryovials and snap-frozen in liquid $\mathrm{N}_{2}$ for biochemical studies. For cryosectioning, hearts were embedded in OCT (Sakura Finotek) and snap-frozen by immersing in liquid $\mathrm{N}_{2}$-chilled isopentane to snap-freeze before storage at $-80^{\circ} \mathrm{C}$.

Co-immunoprecipitation from whole mouse heart tissue. Frozen hearts were weighed and added to lysis buffer (50 mM Hepes pH 7.4, $150 \mathrm{mM} \mathrm{KCl}$, $1 \mathrm{mM}$ EDTA, $1 \mathrm{mM}$ EGTA, $1 \mathrm{mM}$ DTT, $1 \mathrm{mM} \mathrm{NaF}, 100 \mu \mathrm{M} \mathrm{Na}_{3} \mathrm{VO}_{4}, 0.5 \%$ Triton X-100) to a final volume of $200 \mathrm{mg} / \mathrm{ml}$. Tissue was homogenized for 10 seconds and incubated at $4{ }^{\circ} \mathrm{C}$ with rotation for 1 hour before centrifugation at $10,000 \mathrm{~g}$ for 20 minutes to remove insoluble debris. Following protein normalization, lysates were precleared using Dynabeads protein $\mathrm{G}$ (Invitrogen) for 30 minutes at $4^{\circ} \mathrm{C}$ with rotation. Beads were discarded, and $1 \mathrm{mg}$ of precleared lysate was used per reaction. Lysates were incubated for 60 minutes at $4^{\circ} \mathrm{C}$ with rotation with $2 \mu \mathrm{g}$ of primary antibody or mouse anti-GST (Santa Cruz Biotechnology Inc.) as a negative control. Dynabeads protein $\mathrm{G}(15 \mu \mathrm{l})$ was added to each reaction, and tubes were rotated for a further 45 minutes at $4^{\circ} \mathrm{C}$. Beads were washed 4 times for 5 minutes each time with $1 \mathrm{ml}$ lysis buffer on ice using a Dynamag- 2 magnet (Invitrogen). Proteins were eluted from beads in $10 \mu \mathrm{l} 2 \mathrm{X}$ NuPAGE sample buffer and subjected to SDS-PAGE electrophoresis and Western blotting as described above.

Lipid hydroperoxide assay. As a measure of oxidative stress in whole mouse hearts, the lipid hydroperoxide assay kit from Cayman Chemical Company was used. Immediately after Langendorff perfusion experiments, $20 \mathrm{mg}$ of heart tissue was homogenized and chloroform lipid extraction performed as per the manufacturer's instructions. HeLa cells were scraped into icecold water and sonicated prior to lipid extraction. The assay was performed in a glass 96-well dish and absorbance read at $500 \mathrm{~nm}$ using a Spectramax Plus plate reader (Molecular Devices).

Human tissue collection. With the approval of the UCSF Committee for Human Research, we obtained tissue from hearts removed at the time of transplant at UCSF, or from organ donors whose hearts were not transplanted for technical reasons. Fully informed consent was obtained from all UCSF transplant recipients prior to surgery. The California Transplant Donor Network (CTDN) provided the unused donor hearts and obtained informed consent for their use from the next of kin.

Cold cardioplegia was perfused antegrade prior to cardiectomy, and the explanted heart was placed immediately in ice-cold physiologic solution. Full-thickness samples from the base of the left ventricle were cleaned rapidly of all epicardial fat and embedded in OCT medium. The embedded tissue was submerged in liquid $\mathrm{N}_{2}$-chilled isopentane to snap-freeze before storage at $-80^{\circ} \mathrm{C}$.

Patient characteristics. The donor hearts (non-failing) came from four males ages 62-67 without significant past medical history, who sustained irreversible neurological damage secondary to non-cardiac trauma.

The diseased hearts (failing) came from 3 males ages 19-51 and 1 female age 57 , all with end-stage ischemic cardiomyopathy undergoing cardiac transplant at the time of tissue acquisition. Echocardiographic data from one of each patient group are presented in Supplemental Figure 5.

Cryosectioning and immunofluorescence of human and mouse heart tissue. Cryosections $(6 \mu \mathrm{m})$ were prepared and positioned on poly-L-lysine-coated slides prior to acetone fixation and air drying. Sections were outlined using a super PAP pen (Invitrogen) and rehydrated for 10 minutes in PBS. Following 1 hour of blocking at room temperature with 5\% NGS in PBS, sections were incubated at $4{ }^{\circ} \mathrm{C}$ for 16 hours with primary antibodies diluted in 5\% NGS. Primary antibodies used were: Cx43 (rabbit, 1:3,000; SigmaAldrich), EB1 (rabbit, 1:3,000; Sigma-Aldrich), and N-cadherin (mouse, 1:500; BD Biosciences). Following several PBS washes, cells were incubated for an additional hour at room temperature with goat secondary antibodies conjugated to Alexa Fluor 488 or 555 . For detection of N-cadherin in mouse tissue, the same monoclonal mouse anti-N-cadherin antibody was biotinylated using EZ-link sulfo-NHS-SS-biotin and Slide-A-Lyzer dialysis cassettes (Pierce Biotechnology) according to the manufacturer's instructions. Secondary detection was achieved using Streptavidin Alexa Fluor 488 conjugate (1:200; Invitrogen) diluted in high-salt buffer $(0.5 \mathrm{M} \mathrm{NaCl}$, $10 \mathrm{mM}$ Hepes). Slides were washed with PBS, briefly washed with $\mathrm{dH}_{2} \mathrm{O}$, and coverslips were mounted using ProLong gold antifade reagent containing DAPI. Slides were dried overnight and imaged using a Nikon Ti microscope with a $\times 60 / 1.49$ Apo TIRF objective, Yokogowa CSU-X1 spinning disk confocal unit with 486-, 561-, and 647-nm DPSS laser source, and Coolsnap $\mathrm{HQ}^{2}$ camera controlled by NIS Elements software.

Quantification of $\mathrm{C} x 43$ and EB1 at adherens junctions in cryosections by immunofluorescence. N-cadherin overall immunofluorescent signal intensity was found to be associated with overall sample quality, consistent with previous reports (57). For this reason, acquired images were normalized relative to $\mathrm{N}$-cadherin signal before quantif-ication. To isolate intercalated disc regions, ImageJ software was used to subtract background from $\mathrm{N}$-cadherin images, to which equal thresholds were applied, generating binary masks. Within this mask image, intercalated disc regions had a value of 1 and all remaining pixels had a value of 0 . Masks were image-multiplied by corresponding $\mathrm{Cx} 43$ or EB1 images, to exclude all signal except that at the intercalated disc, and fluorescence intensity was subsequently measured. To determine the percent enrichment of EB1 or $\mathrm{Cx} 43$ at intercalated discs relative to overall signal, intercalated disc signal intensities were divided by the overall average signal of EB1 or $\mathrm{Cx} 43$ in the image. For each sample, 6 randomly selected images containing, on average, 31 intercalated discs were analyzed. 
Extraction of human heart soluble (non-junctional) and insoluble (junctional) proteins. Snap-frozen tissue samples were weighed and added to $1 \%$ Triton $\mathrm{X}-100$ buffer $(50 \mathrm{mM}$ Tris pH 7.4, 1\% Triton X-100, 2 mM EDTA, $2 \mathrm{mM}$ EGTA, $250 \mathrm{mM} \mathrm{NaCl}, 1 \mathrm{mM} \mathrm{NaF}, 0.1 \mathrm{mM} \mathrm{Na}_{3} \mathrm{VO}_{4}$, Complete Mini protease inhibitors) at a final concentration of $100 \mathrm{mg}$ tissue $/ \mathrm{ml}$. Samples were homogenized and nutated for 1 hour at $4{ }^{\circ} \mathrm{C}$. At this point, $300 \mu$ l of lysate was removed and added to an equal volume of $1 \%$ Triton X-100 buffer containing $8 \mathrm{M}$ urea and $2 \mathrm{M}$ thiourea (Sigma-Aldrich) in order to solubilize junctional proteins and generate the total protein fraction. The remaining lysate was centrifuged for 20 minutes at $10,000 \mathrm{~g}$ in pre-weighed microcentrifuge tubes. Supernatant was removed and added to an equal volume of $1 \%$ Triton X-100 buffer containing $8 \mathrm{M}$ urea and $2 \mathrm{M}$ thiourea for the soluble protein fraction. Pellets were weighed and suspended in $1 \%$ Triton $\mathrm{X}-100$ buffer containing $4 \mathrm{M}$ urea and $1 \mathrm{M}$ thiourea to a final concentration of $30 \mathrm{mg} / \mathrm{ml}$. A motorized pestle was used to dissolve the pellet and generate the insoluble protein fraction. NuPAGE sample buffer was added to all fractions prior to sonication and centrifugation for 20 minutes at $10,000 \mathrm{~g}$. DTT was added to a final concentration of $100 \mathrm{mM}$ and samples reduced for 30 minutes at $37^{\circ} \mathrm{C}$ before subjection to SDS-PAGE electrophoresis and Western blotting, as described above. Negligible differences in extraction of insoluble $\mathrm{Cx} 43$ were detected using solubilization buffers containing SDS or with higher concentrations of urea. Once quantified, all values were normalized to $\alpha$-tubulin, and subsequently soluble and insoluble values were normalized to the appropriate control amounts of $\mathrm{Cx} 43$.

Preparation of whole protein lysates from human and mouse heart tissue. Tissue was homogenized in RIPA buffer, sonicated, and prepared for Western blotting as described above.

EB1-K89E expression for Cx43 surface biotinylation. pLenti6.3-Cx43 HeLa cells were plated in 100-mm dishes at a concentration of $10^{6}$ cells/dish and allowed to adhere overnight. Cells were transfected with pcDNA3.1-V5-EB1 or pcDNA3.1-V5-EB1-K89E ( $5 \mu \mathrm{g} / \mathrm{dish})$ using Lipofectamine LTX (Invitrogen) according to the manufacturer's instructions. After transfection, the medium was changed and Dynasore added to a final concentration of $80 \mu \mathrm{M}$. Biotinylation was performed as described above 36 hours after transfection.
Quantification of Western blotting. All blots were imaged using the Versadoc 4000 MP (BioRad). Flat-fielding was used, and Quantity One (BioRad) analysis software was used to quantify individual bands. Samples were normalized to GAPDH, $\alpha$-tubulin, or $\beta$-actin. Graphs were plotted and statistics performed using Prism 5 software (GraphPad).

Statistics. All quantitative data were analyzed using Prism 5 software (GraphPad) and expressed as mean \pm SEM. A 2-tailed unpaired Student's $t$ test was used to analyze data containing 2 groups, and a 1-way ANOVA with Bonferroni post-test was used to analyze data with 3 or more groups. In both cases, a $P$ value less than 0.05 was deemed statistically significant.

\section{Acknowledgments}

The authors are grateful to Kevin Chu, José Sanchez, Lily Jan, and Samy Lamouille (UCSF) for critical review of this manuscript, Farah Sheikh for technical advice on tissue fractionation, Ivy Hsieh and Margaret Mayes for tissue cryosectioning, and Sean Van Slyck (California Transplant Donor Network) for human tissue. This work was supported in part by the American Federation for Aging Research grant A112457 (to J.W. Smyth), the Young Investigators Award from the GlaxoSmithKline Research and Education Foundation for Cardiovascular Disease (to B.C. Jensen and R.M. Shaw), the UCSF Foundation for Cardiac Research (to B.C. Jensen), the Department of Veterans Affairs Research Service (to P.C. Simpson), and NIH grants HL31113 (to P.C. Simpson), HL54737 (to D.Y.R. Stainier), and HL094414 and HL075449 (to R.M. Shaw).

Received for publication May 4, 2009, and accepted in revised form November 11, 2009.

Address correspondence to: Robin M. Shaw, 505 Parnassus Avenue, San Francisco, California 94143-0124, USA. Phone: (415) 476-0626; Fax (415) 476-0424; E-mail: shawrm@medicine.ucsf.edu.
1. Shaw RM, Rudy Y. Ionic mechanisms of propagation in cardiac tissue. Roles of the sodium and L-type calcium currents during reduced excitability and decreased gap junction coupling. Circ Res. 1997;81(5):727-741.

2. Gros DB, Jongsma HJ. Connexins in mammalian heart function. Bioessays. 1996;18(9):719-730.

3. Luke RA, Saffitz JE. Remodeling of ventricular conduction pathways in healed canine infarct border zones. J Clin Invest. 1991;87(5):1594-1602.

4. Beardslee MA, et al. Dephosphorylation and intracellular redistribution of ventricular connexin 43 during electrical uncoupling induced by ischemia. Circ Res. 2000;87(8):656-662.

5. Akar FG, et al. Dynamic changes in conduction velocity and gap junction properties during development of pacing-induced heart failure. Am J Physiol Heart Circ Physiol. 2007;293(2):H1223-H1230.

6. Smith JH, Green CR, Peters NS, Rothery S Severs NJ. Altered patterns of gap junction distribution in ischemic heart disease. An immunohistochemical study of human myocardium using laser scanning confocal microscopy. Am J Pathol. 1991;139(4):801-821.

7. Peters NS, Coromilas J, Severs NJ, Wit AL. Disturbed connexin 43 gap junction distribution correlates with the location of reentrant circuits in the epicardial border zone of healing canine infarcts that cause ventricular tachycardia. Circulation. 1997;95(4):988-996.

8. Kalcheva N, et al. Gap junction remodeling and cardiac arrhythmogenesis in a murine model of oculodentodigital dysplasia. Proc Natl Acad Sci U S A.
2007;104(51):20512-20516.

9. Poelzing S, Rosenbaum DS. Altered connexin43 expression produces arrhythmia substrate in heart failure. Am J Physiol Heart Circ Physiol. 2004;287(4):H1762-H1770.

10. Saez JC, Berthoud VM, Branes MC, Martinez AD, Beyer EC. Plasma membrane channels formed by connexins: their regulation and functions. Physiol Rev. 2003;83(4):1359-1400.

11. Sohl G, Willecke K. Gap junctions and the connexin protein family. Cardiovasc Res. 2004;62(2):228-232.

12. Beyer EC, Paul DL, Goodenough DA. Connexin 43: a protein from rat heart homologous to a gap junction protein from liver. $J$ Cell Biol. 1987;105(6 Pt 1):2621-2629.

13. Wei CJ, Francis R, Xu X, Lo CW. Connexin 43 associated with an $\mathrm{N}$-cadherin-containing multiprotein complex is required for gap junction formation in NIH3T3 cells. J Biol Chem. 2005;280(20):19925-19936.

14. Nambara C, Kawasaki Y, Yamasaki H. Role of the cytoplasmic loop domain of $\mathrm{Cx} 43$ in its intracellular localization and function: possible interaction with cadherin. J Membr Biol. 2007;217(1-3):63-69.

15. Matsuda T, et al. N-cadherin signals through Rac1 determine the localization of connexin 43 in cardiac myocytes. J Mol Cell Cardiol. 2006;40(4):495-502.

16. Li J, et al. Cardiac-specific loss of $\mathrm{N}$-cadherin leads to alteration in connexins with conduction slowing and arrhythmogenesis. Circ Res. 2005;97(5):474-481.

17. Giepmans BN, et al. Gap junction protein connexin-43 interacts directly with microtubules. Curr Biol. 2001;11(17):1364-1368.
18. Lauf U, Giepmans BN, Lopez P, Braconnot S, Chen SC, Falk MM. Dynamic trafficking and delivery of connexons to the plasma membrane and accretion to gap junctions in living cells. Proc Natl Acad SciUS A. 2002;99(16):10446-10451.

19. Jordan K, et al. Trafficking, assembly, and function of a connexin43-green fluorescent protein chimera in live mammalian cells. Mol Biol Cell. 1999;10(6):2033-2050.

20. Kang EY, Ponzio M, Gupta PP, Liu F, Butensky A, Gutstein DE. Identification of binding partners for the cytoplasmic loop of connexin43: a novel interaction with beta-tubulin [published online ahead of print March 9, 2009]. Cell Commun Adhes. doi:10.1080/15419060902783833.

21. Thomas T, Jordan K, Laird DW. Role of cytoskeletal elements in the recruitment of Cx43-GFP and Cx26-YFP into gap junctions. Cell Commun Adhes. 2001;8(4-6):231-236.

22. Gelfand VI, Bershadsky AD. Microtubule dynamics: mechanism, regulation, and function. Annu Rev Cell Biol. 1991;7:93-116.

23. Lansbergen G, Akhmanova A. Microtubule plus end: a hub of cellular activities. Traffic. 2006;7(5):499-507.

24. Shaw RM, Fay AJ, Puthenveedu MA, von Zastrow M, Jan YN, Jan LY. Microtubule plus-endtracking proteins target gap junctions directly from the cell interior to adherens junctions. Cell. 2007;128(3):547-560.

25. Ligon LA, Holzbaur EL. Microtubules tethered at epithelial cell junctions by dynein facilitate efficient junction assembly. Traffic. 2007;8(7):808-819. 
26. Mimori-Kiyosue Y, Tsukita S. "Search-and-capture" of microtubules through plus-end-binding proteins (+TIPs). J Biochem. 2003;134(3):321-326.

27. Jamora C, Fuchs E. Intercellular adhesion, signalling and the cytoskeleton. Nat Cell Biol. 2002;4(4):E101-E108.

28. Ferrari R, et al. Occurrence of oxidative stress during reperfusion of the human heart. Circulation. 1990;81(1):201-211.

29. Dewald O, et al. Development of murine ischemic cardiomyopathy is associated with a transient inflammatory reaction and depends on reactive oxygen species. Proc Natl Acad Sci U S A. 2003;100(5):2700-2705.

30. Becker LB. New concepts in reactive oxygen species and cardiovascular reperfusion physiology. Cardiovasc Res. 2004;61(3):461-470.

31. Ferrari R, et al. Oxidative stress during myocardial ischaemia and heart failure. Eur Heart J. 1998;19(Suppl B):B2-B11.

32. Nojiri $\mathrm{H}$, et al. Oxidative stress causes heart failure with impaired mitochondrial respiration. J Biol Chem. 2006;281(44):33789-33801.

33. Iwai $\mathrm{K}$, et al. Disruption of microtubules as an early sign of irreversible ischemic injury. Immunohistochemical study of in situ canine hearts. Circ Res. 1990;67(3):694-706.

34. Vandroux D, et al. Microtubule alteration is an early cellular reaction to the metabolic challenge in ischemic cardiomyocytes. Mol Cell Biochem. 2004;258(1-2):99-108

35. Lee CF, Liu CY, Hsieh RH, Wei YH. Oxidative stress-induced depolymerization of microtubules and alteration of mitochondrial mass in human cells. Ann N Y Acad Sci. 2005;1042:246-254.

36. Beardslee MA, Laing JG, Beyer EC, Saffitz JE. Rapid turnover of connexin 43 in the adult rat heart. Circ Res. 1998;83(6):629-635.

37. Gaietta G, et al. Multicolor and electron microscopic imaging of connexin trafficking. Science. 2002;296(5567):503-507.

38. Hunter AW, Barker RJ, Zhu C, Gourdie RG. Zonula occludens- 1 alters connexin 43 gap junction size and organization by influencing channel accretion. Mol Biol Cell. 2005;16(12):5686-5698.

39. Musil LS, Goodenough DA. Biochemical analysis of connexin 43 intracellular transport, phosphorylation, and assembly into gap junctional plaques. J Cell Biol. 1991;115(5):1357-1374.
40. Bruce AF, Rothery S, Dupont E, Severs NJ. Gap junction remodelling in human heart failure is associated with increased interaction of connexin 43 with ZO-1. Cardiovasc Res. 2008;77(4):757-765.

41. Gumpert AM, Varco JS, Baker SM, Piehl M, Falk MM. Double-membrane gap junction internalization requires the clathrin-mediated endocytic machinery. FEBS Lett. 2008;582(19):2887-2892.

42. Macia E, Ehrlich M, Massol R, Boucrot E, Brunner C, Kirchhausen T. Dynasore, a cell-permeable inhibitor of dynamin. Dev Cell. 2006;10(6):839-850.

43. Axelrod D. Cell-substrate contacts illuminated by total internal reflection fluorescence. J Cell Biol. 1981;89(1):141-145.

44. Smyth JW, Shaw RM. Visualizing ion channel dynamics at the plasma membrane. Heart Rhythm. 2008;5(6 Suppl):S7-S11.

45. Urlinger S, Baron U, Thellmann M, Hasan MT, Bujard $\mathrm{H}$, Hillen W. Exploring the sequence space for tetracycline-dependent transcriptional activators: novel mutations yield expanded range and sensitivity. Proc Natl Acad Sci U S A. 2000;97(14):7963-7968.

46. Hayashi I, Ikura M. Crystal structure of the amino-terminal microtubule-binding domain of end-binding protein 1 (EB1). J Biol Chem. 2003;278(38):36430-36434.

47. Nakai J, Ohkura M, Imoto K. A high signal-to-noise $\mathrm{Ca}(2+)$ probe composed of a single green fluorescent protein. Nat Biotechnol. 2001;19(2):137-141.

48. Chi NC, et al. Genetic and physiologic dissection of the vertebrate cardiac conduction system. PLoS Biol. 2008;6(5):e109.

49. Kieken F, et al. Structural and molecular mechanisms of gap junction remodeling in epicardial border zone myocytes following myocardial infarction. Circ Res. 2009;104(9):1103-1112.

50. Jordan K, Chodock R, Hand AR, Laird DW. The origin of annular junctions: a mechanism of gap junction internalization. JCell Sci. 2001;114(Pt 4):763-773.

51. Erickson JR, et al. A dynamic pathway for calciumindependent activation of CaMKII by methionine oxidation. Cell. 2008;133(3):462-474.

52. Fukuda K, et al. Oxidative mediated lipid peroxidation recapitulates proarrhythmic effects on cardiac sodium channels. Circ Res. 2005;97(12):1262-1269.

53. Lowe JS, et al. Voltage-gated Nav channel targeting in the heart requires an ankyrin-G dependent cellular pathway. J Cell Biol. 2008;180(1):173-186.

54. Mohler PJ, et al. Ankyrin-B mutation causes type
4 long-QT cardiac arrhythmia and sudden cardiac death. Nature. 2003;421(6923):634-639.

55. Sorgen PL, Duffy HS, Sahoo P, Coombs W, Delmar M, Spray DC. Structural changes in the carboxyl terminus of the gap junction protein connexin 43 indicates signaling between binding domains for c-Src and zonula occludens-1. J Biol Chem. 2004;279(52):54695-54701.

56. Qu Z, Karagueuzian HS, Garfinkel A, Weiss JN. Effects of $\mathrm{Na}(+)$ channel and cell coupling abnormalities on vulnerability to reentry: a simulation study. Am J Physiol Heart Circ Physiol. 2004;286(4):H1310-H1321.

57. Asimaki A, et al. A new diagnostic test for arrhythmogenic right ventricular cardiomyopathy. $N$ Engl JMed. 2009;360(11):1075-1084.

58. Saffitz JE. Dependence of electrical coupling on mechanical coupling in cardiac myocytes: insights gained from cardiomyopathies caused by defects in cell-cell connections. Ann N Y Acad Sci. 2005;1047:336-344.

59. Saffitz JE. Arrhythmogenic cardiomyopathy and abnormalities of cell-to-cell coupling. Heart Rhythm. 2009;6(8 Suppl):S62-S65.

60. McKoy G, et al. Identification of a deletion in plakoglobin in arrhythmogenic right ventricular cardiomyopathy with palmoplantar keratoderma and woolly hair (Naxos disease). Lancet. 2000;355(9221):2119-2124.

61. Gutstein DE, et al. Conduction slowing and sudden arrhythmic death in mice with cardiacrestricted inactivation of connexin 43. Circ Res. 2001;88(3):333-339.

62. Danik SB, et al. Modulation of cardiac gap junction expression and arrhythmic susceptibility. Circ Res. 2004;95(10):1035-1041.

63. Duffy HS, et al. Regulation of connexin 43 protein complexes by intracellular acidification. Circ Res. 2004;94(2):215-222.

64. Wittmann T, Bokoch GM, Waterman-Storer CM. Regulation of leading edge microtubule and actin dynamics downstream of Rac1. J Cell Biol. 2003;161(5):845-851.

65. Arnaout R, et al. Zebrafish model for human long QT syndrome. Proc Natl Acad Sci U S A. 2007;104(27):11316-11321.

66. Bagatto B, Francl J, Liu B, Liu Q. Cadherin2 (N-cadherin) plays an essential role in zebrafish cardiovascular development. BMC Dev Biol. 2006;6:23. 